\title{
Inter- and intra-specific pan-genomes of Borrelia burgdorferi sensu lato: genome stability and adaptive radiation
}

Emmanuel F Mongodin ${ }^{1 *}$, Sherwood R Casjens ${ }^{2}$, John F Bruno ${ }^{3}$, Yun Xu ${ }^{3}$, Elliott Franco Drabek ${ }^{1}$, David R Riley ${ }^{1}$, Brandi L Cantarel ${ }^{1}$, Pedro E Pagan ${ }^{4}$, Yozen A Hernandez ${ }^{4}$, Levy C Vargas ${ }^{4}$, John J Dunn ${ }^{5^{\wedge}}$, Steven E Schutzer ${ }^{6}$, Claire M Fraser ${ }^{1}$, Wei-Gang Qiu ${ }^{4^{*}}$ and Benjamin J Luft ${ }^{3^{*}}$

\begin{abstract}
Background: Lyme disease is caused by spirochete bacteria from the Borrelia burgdorferi sensu lato (B. burgdorferi s.l.) species complex. To reconstruct the evolution of $B$. burgdorferi s.l. and identify the genomic basis of its human virulence, we compared the genomes of 23 B. burgdorferi s.l. isolates from Europe and the United States, including B. burgdorferi sensu stricto (B. burgdorferi s.s., 14 isolates), B. afzelii (2), B. garinii (2), B. "bavariensis" (1), B. spielmanii (1), B. valaisiana (1), B. bissettii (1), and B. "finlandensis" (1).

Results: Robust B. burgdorferi s.s. and B. burgdorferi s.l. phylogenies were obtained using genome-wide single-nucleotide polymorphisms, despite recombination. Phylogeny-based pan-genome analysis showed that the rate of gene acquisition was higher between species than within species, suggesting adaptive speciation. Strong positive natural selection drives the sequence evolution of lipoproteins, including chromosomally-encoded genes 0102 and 0404, cp26-encoded ospC and b08, and Ip54-encoded dbpA, a07, a22, a33, a53, a65. Computer simulations predicted rapid adaptive radiation of genomic groups as population size increases.

Conclusions: Intra- and inter-specific pan-genome sizes of B. burgdorferi s.l. expand linearly with phylogenetic diversity. Yet gene-acquisition rates in B. burgdorferi s.l. are among the lowest in bacterial pathogens, resulting in high genome stability and few lineage-specific genes. Genome adaptation of B. burgdorferi s.l. is driven predominantly by copy-number and sequence variations of lipoprotein genes. New genomic groups are likely to emerge if the current trend of B. burgdorferi s.l. population expansion continues.
\end{abstract}

Keywords: Borrelia burgdorferi, Lyme borreliosis, Pan-genome, Single-nucleotide polymorphisms, Phylogenetic tree, Genome evolution simulation

\section{Background}

Lyme disease, caused by the spirochete bacteria Borrelia burgdorferi, has become the most common vector-borne disease in the United States and Europe [1]. The genome organization of the bacterium and the spectrum of clinical

\footnotetext{
*Correspondence: emongodin@som.umaryland.edu; weigang@genectr. hunter.cuny.edu; bluft@notes.cc.sunysb.edu

Deceased

'Institute for Genome Sciences, University of Maryland School of Medicine, Baltimore, Maryland 21201, USA

${ }^{4}$ Department of Biological Sciences, Hunter College of the City University of New York, New York, New York 10065, USA

${ }^{3}$ Department of Medicine, Health Science Center, Stony Brook University,

Stony Brook, New York 11794, USA

Full list of author information is available at the end of the article
}

manifestations associated with Lyme disease have presented a number of research challenges. Lyme disease is frequently a multisystem infection, commonly affecting the skin, joints, and central nervous system in humans $[2,3]$, yet at other times the symptoms are restricted to the skin. Although much of the attention on B. burgdorferi involves the disease in humans, there is a complex relationship between the microbe in its vector, the Ixodes tick, the animals it can infect, and the environment. For example, the prevalence of $B$. burgdorferi is associated with the geographic range and abundance of its host species rather than its tick (Ixodes scapularis) vector [4-6]. Although it has been found in many vertebrates in the United States, 
white-footed mice (Peromyscus leucopus) and eastern chipmunks (Tamias striatus) serve as major maintenance reservoirs of $B$. burgdorferi; however, there may be other preferred host species for different local strains $[7,8]$. In Europe, B. burgdorferi (as well as B. garinii and B. afzelii which also cause Lyme disease) is transmitted by Ixodes ricinus ticks [9] and is carried by a large variety of hosts including birds and small-to-medium sized mammals [10]. For many reasons Lyme disease remains a puzzling emerging disease $[3,11]$.

Globally, the B. burgdorferi species complex [12], $B$. burgdorferi sensu lato (B. burgdorferi s.l.), is classified into different genomic groups or species (sometimes called "genospecies") on the basis of their molecular phylogeny. These species differ by $1 \%-2 \%$ in the $16 \mathrm{~S}$ ribosomal RNA sequences [13] and by about $9 \%$ in average genome sequences where the latter is known [14] (see below). The most common species in North America are B. burgdorferi sensu stricto ( $B$. burgdorferi s.s.) in the northeast and north central parts of the United States and B. bissettii in California and the western United States [15-18]. The most common species in Europe are B. garinii [19], B. afzelii [20], B. burgdorferi s.s., B. valaisiana and $B$ spielmanii $[9,21]$. B. garinii, B. afzelii, and B. valaisiana are also common in northern Asia, but $B$. burgdorferi s.s. is absent from eastern Asia [22]. The three species $B$. burgdorferi s.s., B. garinii, and B. afzelii are the most common pathogens of Lyme disease, and they are each associated with different clinical manifestations of chronic Lyme disease [3,23]. More recently B. bissettii, B. lusitaniae, $B$. spielmanii and $B$. valaisiana have been isolated from human patients [24-29]. A series of molecular genotyping assays using genome-wide sequence signatures and individual loci have found genetic differentiation between the two continental B. burgdorferi s.s. populations, a European origin of the North American populations, and a few shared genotypes between the European and North American populations perhaps caused by contemporary migrations [30-33]. Intriguingly, we find that genotypes characterized as highly pathogenic in humans are also the ones that have a broad host-species range, able to colonize both continents [34].

Intra-specific lineages of $B$. burgdorferi s.s. can be differentiated by $16 \mathrm{~S}-23 \mathrm{~S}$ ribosomal RNA spacer (IGS) and outer surface protein $C$ gene $(o s p C)$ sequences [35-38]. It has been found that these different intra-specific lineages may be related to different levels of pathogenicity. For example, a particular restriction fragment length polymorphism (RFLP) in the $B$. burgdorferi IGS sequence and ospC type are associated with hematogenous dissemination in patients with early stage Lyme disease [39-41]. A significant number of $\operatorname{ssp} C$ clonal types associated with invasive disease in humans have also been found in B. afzelii and $B$. garinii [42]; however, the ospC clonal types isolated from patients with invasive disease are not limited to those types [43]. These subtypes have been further subdivided using a broad range primer assay coupled with mass spectrometry [44]. However, none of these studies examined entire genomes in its entirety, so conclusions remain limited.

The overall objective of the study reported here was to develop an informative genome-wide picture of $B$. burgdorferi diversity, with the ultimate aim of understanding how variations in genomic composition may lead to variations in pathogenicity. Although this study did not examine the molecular basis of Lyme disease per se, we believe it will greatly enhance such studies in many ways. For example, conserved genome features should in principle be those likely to be most essential in the Borrelia life cycle, while variable ones might be those that are more important immunologically and ecotypically. The present study was undertaken to help the scientific community generate hypotheses about what genes are related to human disease or of ecologic importance in the life cycle of this pathogen. Furthermore, such studies should provide some insight as to whether there is potential for the non-Lyme disease causing species to serve as a reservoir of genetic diversity for those that cause Lyme disease.

\section{Results and discussion}

Harvesting the genomic diversity of the Lyme agent through selection of Borrelia strains for whole-genome shotgun sequencing

Research efforts aimed at deciphering the mechanisms of Borrelia pathogenicity have resulted in significant progress over the past few years [45]. However, the costs and difficulties for propagation of the bacteria in culture, the prolonged doubling time of Borrelia, in addition to the limited tools that are available for genetic manipulation, have presented a number of significant challenges. Therefore, rigorous genetic studies and biochemical approaches that require even moderate amounts of biological materials are expensive, technically difficult and slow. Because of recent dramatic reductions in the DNA sequencing costs, comparative genomics studies of Borrelia species are now a cost effective way to provide a firm foundation for the generation of new, informed, and testable hypotheses which would be difficult or impossible to formulate by other means.

The Borrelia genus contains two major clades, one that includes the Lyme disease agents, and another that includes the relapsing fever agents, each of which contains numerous species $[12,46,47]$. Variation among B. burgdorferi isolates has most recently been analyzed informatively using MLST analyses [33,48,49]. In order to choose a panel of isolates for genome sequencing that maximized the represented $B$. burgdorferi s.s. genetic diversity, we MLST-typed 64 such isolates (Figure 1) that reside in different major groups based on rRNA IGS1 spacer sequence $[35,38]$ and $o s p C$ sequence $[35,36]$ while also attempting 


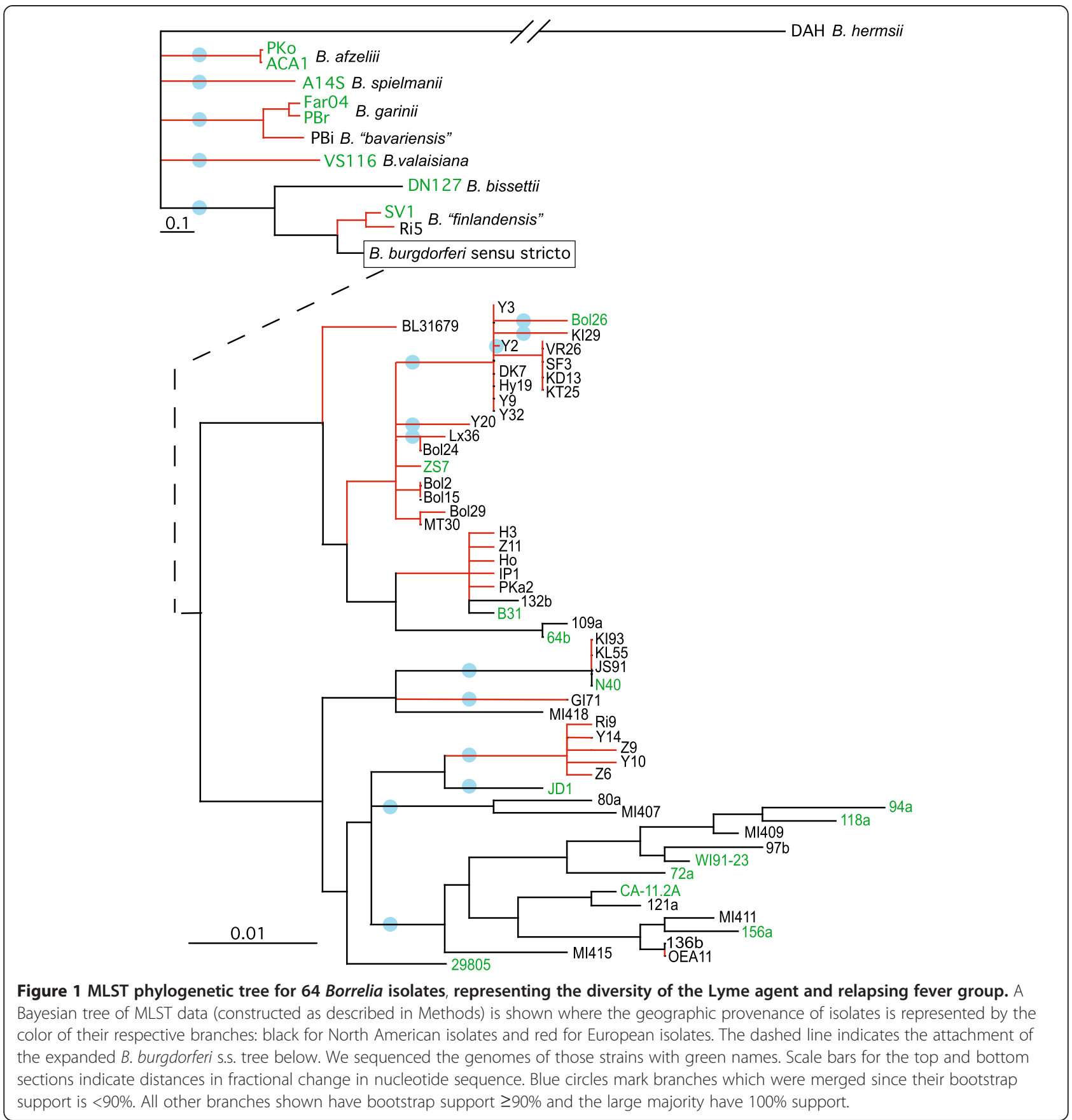

to include a variety of hosts and geographical regions. In addition, we included geographically diverse $B$. burgdorferi s.l. isolates, including several species that are not known to commonly cause Lyme disease. Twenty-two isolates were chosen for sequencing that included most of the major branches of this MLST tree (Table 1).

These isolates include $14 \mathrm{~B}$. burgdorferi s.s. strains (in one of these, strain 297, the chromosome was not sequenced) which include six isolates from ticks (including ones from Ixodes scapularis, I. pacificus and I. ricinus), a wild bird isolate (from a Song Sparrow, Melospiza melo$\mathrm{dia}$ ), and seven isolates from human Lyme disease patients [50]. Within these s.s. isolates, considerable geographic distribution is also present, and it includes isolates from California, Wisconsin, New York, Massachusetts and Connecticut as well as Germany and Italy. In addition, eight other B. burgdorferi s.l. strains were chosen for sequencing, including two B. afzelii (Sweden and Germany), two B. garinii (Denmark and Germany) [51], single $B$. bissettii (California), B. spielmanii (The Netherlands) and 
Table 1 Borrelia isolates analyzed in this study

\begin{tabular}{|c|c|c|c|c|c|c|c|}
\hline Species & Strain & rRNA IGS lineage & ospC type & Genome status & No. of plasmids & $\mathrm{GPID}^{a}$ & Isolation and sequence references \\
\hline \multirow[t]{14}{*}{ B. burgdorferi } & B31 & 1 & A & Complete & 21 & 3 & {$[57,86,112]$} \\
\hline & Bol26 & 3 & S & Draft & 13 & 19837 & {$[34,50]$} \\
\hline & ZS7 & 16 & $\mathrm{Bb}$ & Draft & 14 & 19839 & {$[50,113]$} \\
\hline & $64 b$ & 3 & $\mathrm{Ba}$ & Draft & 18 & 28633 & {$[50,114]$} \\
\hline & 297 & 2 & K & Complete $^{b}$ & 20 & 39123 & {$[50,115]$} \\
\hline & $156 a$ & 12 & $\mathrm{Hb}$ & Complete & 20 & 19835 & {$[50,114]$} \\
\hline & WI-91-23 & 7 & la & Draft & 21 & 28627 & {$[50,116]$} \\
\hline & $94 a$ & 8 & U & Draft & 14 & 20999 & {$[50,114]$} \\
\hline & JD1 & 24 & C & Complete & 20 & 39121 & {$[50,117]$} \\
\hline & CA-11.2A & 19 & $\mathrm{Dd}$ & Draft & 12 & 28629 & {$[50,118]$} \\
\hline & $118 a$ & 20 & J & Draft & 19 & 21001 & {$[50,114]$} \\
\hline & $\mathrm{N} 40$ & 9 & $E$ & Complete & 17 & 39119 & {$[50,119]$} \\
\hline & $72 a$ & 26 & G & Draft & 13 & 21003 & {$[50,114]$} \\
\hline & 29805 & 6 & M & Draft & 15 & 28621 & {$[50,120]$} \\
\hline B. "finlandensis" & SV1 & - & - & Draft & 10 & 28631 & {$[34,53]$} \\
\hline B. valaisiana & VS116 & - & - & Draft & 11 & 19843 & {$[52,121]$} \\
\hline B. bissettii & DN127 & - & - & Complete & 16 & 29363 & {$[52,122]$} \\
\hline \multirow[t]{2}{*}{ B. afzelii } & PKo & - & - & Complete & 17 & 68149,17057 & {$[51,54,123]$} \\
\hline & ACA-1 & - & - & Draft & 14 & 19841 & {$[51,124]$} \\
\hline \multirow[t]{2}{*}{ B. garinii } & $\mathrm{PBr}$ & - & - & Draft & 12 & 28625 & {$[51,123]$} \\
\hline & Far04 & - & - & Draft & 7 & 29573 & {$[51,125]$} \\
\hline B. "bavariensis" & $\mathrm{PBi}$ & - & - & Incomplete & $(11)^{c}$ & 58125 & {$[14,48,126]$} \\
\hline B. spielmanii & A14S & - & - & Draft & 13 & 28635 & {$[52,127]$} \\
\hline
\end{tabular}

${ }^{a}$ Genome Project ID. Data from each genome can be retrieved directly from the NCBI Entrez Genome Project Database (http://www.ncbi.nlm.nih.gov/bioproject) using the Genbank Genome Project ID.

${ }^{\mathrm{b}}$ For B. burgdorferi strain 297, all the plasmids have been identified and sequenced to closure. However, the chromosome of 297 was not sequenced.

'The complete sequences for all strain PBi plasmids have not yet been reported.

B. valaisiana (Switzerland) isolates [52], and one isolate that may be an uncharacterized species (tick isolate SV1 from Finland) [53]. The latter seven isolates include human, bird (Atlantic Puffin, Fratercula arctica) and tick (I. ricinus) isolates. Table 1 lists the isolates whose genomes we analyze in this report along with their rRNA IGS and $\operatorname{sp} C$ types. In addition, the chromosome and some plasmid sequences have been reported for $B$. "bavariensis" strain PBi [14,54], so altogether the sequences of 22 chromosomes and 345 plasmid sequences have been reported from 23 B. burgdorferi s.l. genomes.

\section{Borrelia chromosomal diversity}

Chromosomal sequences from the above thirteen strains of B. burgdorferi s.s. and nine other Borrelia s.l. isolates were aligned using the Mugsy genome aligner to compute a conserved chromosomal core sequence alignment which consisted of $843,710 \mathrm{bp}$ of nucleotide sequence present in all chromosome sequences (see Methods for details). The difference between this value and the $\sim 903,000 \mathrm{bp}$ of the chromosomal constant regions (see below) is nearly all due to gaps between contigs in the draft chromosome sequences. In agreement with various less comprehensive methods [16,55], we find that the chromosomes of different isolates and species of $B$. burgdorferi s.l. are syntenic and conserved across nearly the entire length of the chromosome.

Length differences of up to about $20 \mathrm{kbp}$ among $B$. burgdorferi chromosomes are due to different lengths of plasmid-like DNA sequences attached to their right ends ([56-58] and our unpublished analysis). The constant chromosomal region spans approximately $903 \mathrm{kbp}$ located at the left end of the chromosome, and is delimited by type-strain B31 genes b31_0001 through b31_0843 (for gene description and nomenclature in this report, we use the nomenclature schema recommended by Casjens et al. [59] in which the isolate name in lower case precedes the number part of the GenBank locus tag; this naming strategy, unlike previous ones, distinguishes orthologues from different isolates. We furthermore recommend not using the strain specific prefix, e.g., "b31_", when referring to a generic set of orthologues). In order to have consistent 
annotations across all the chromosomes sequenced, the B31 genome annotation was refreshed during this study and now predicts 815 genes in this region, which occupy 93.5\% of the chromosome constant region (Accession Nos. AE000783-794 and AE001575-1584). We examined three of the B. burgdorferi chromosomes for open reading frame differences and disruptions, and found 18, 2 and 6 disruptions in strains B31, N40 and JD1, respectively (Additional file 1: Table S1). Some of the apparent disruptions in B31 are likely due to sequencing errors, since base calling and genome assembly were less accurate in 1997 when strain B31 was originally sequenced, There are very few obviously disrupted genes in the constant regions of these chromosomes.

The constant regions of the B. burgdorferi s.s. linear chromosomes are remarkably similar. Nucleotide differences between the thirteen chromosomes range from only $0.084 \%$ (strain ZS7 compared to Bol26) to $0.625 \%$ (strain 94a compared to 29805) (Table 2). Furthermore, only four indels larger than $30 \mathrm{bp}$ are present. A 157-bp deletion appears to inactivate chromosomal gene 0021, which is predicted to encode the tRNA modification enzyme that synthesizes queuosine in a number of the $B$. burgdorferi sequences, and variable numbers of tandem repeat sequences are present in three genes 0210, 0546 and 0801 (details in Additional file 2: Table S2) (no strain indicator is included here in the names of orthologous gene sets; see [59] for gene nomenclature). Gene b31_0210 encodes the surface protein Lmp1 that may be required for host serum resistance [60,61], and b31_0546 and b31_0801 encode a protein of unknown function and translation initiation factor 2, respectively (no other repeat-containing chromosomal genes were found with TandemRepeatsFinder [62]). In the B. burgdorferi s.s. chromosomes, the numbers of these repeats vary from 5 to 8,3 to 5 and 10 to 12 , respectively, in these three genes (Additional file 2: Table S2), so these variable number tandem repeat (VNTR) loci should be useful for lineage or epidemic tracking in Borrelia.

The chromosomes of $B$. burgdorferi isolate B31, one $B$. "bavariensis" isolate (strain $\mathrm{PBi}$ ), and one B. afzelii (PKo) isolate species have previously been reported to have nearly identical gene content $[14,54]$. We confirm these observations and extend them to additional species. Our data show that the sequences of B. burgdorferi, B. afzelii, B. garinii and B. valaisiana chromosomes are from $6.5 \%$ to $8.0 \%$ different from one another in between-species comparisons (Table 2). The chromosomes of $B$. bissettii, B. spielmanii and B. "bavariensis" (isolate $\mathrm{PBi}$ ) are $5.0 \%$ different from B. burgdorferi, $5.3 \%$ different from B. afzelii and $2.2 \%$ different from $B$. garinii, respectively. The chromosome of the Finland isolate SV1 is $1.75 \pm 0.3 \%$ different from the B. burgdorferi s.s. isolates (Table 2), and its plasmids are quite different from those of $B$. burgdorferi (our unpublished analysis). Thus, if as has been suggested by Margos and colleagues [48] isolate PBi represents a newly defined species $B$. "bavariensis", then isolate SV1 might also be considered as representative of another previously undefined species, for which we have suggested the name $B$. "finlandensis" [53]. The observed differences between isolates within species, $0.35 \pm 0.27 \%, 0.23 \%$ and $0.80 \%$ for B. burgdorferi s.s., B. afzelii and $B$. garinii, respectively, are all considerably less than inter-species values and so robustly confirm these existing groupings (Table 2).

We have not performed an exhaustive comparison of the indels that relate the constant region of the B. burgdorferi s.s. chromosome to those of the other B. burgdorferi s.l. species, but nearly all of the B. burgdorferi chromosomal genes are present in chromosomes of each of the s.l. species. For example, our comparison of $B$. burgdorferi and B. afzelii shows that in addition to interspecies differences in the three repeat-containing genes mentioned above, we find only eleven indels larger than $25 \mathrm{bp}$ that differentiate the chromosomes of the two species (Additional file 3: Table S3). Compared to strain $\mathrm{B} 31$, these include the previously described duplications in the bmp gene region in strains PBi and PKo [54,63], the differential presence of two genes (0138 and 0223), five indels $<330 \mathrm{bp}$ long between genes, and indels of $<150$ bp in genes 0309, 0704 and 0749. In addition, both B. afzelii isolates PKo and ACA-1 have an apparent duplication of the $16 \mathrm{~S}$ rRNA gene region relative to other B. burgdorferi s.l. isolates. We note that the above nonVNTR indels are the same in the chromosomes of both sequenced B. afzelii genomes (Additional file 3: Table S3), again indicating the very similar nature of chromosomes within each species. Finally, an unusually variable region of the chromosome was identified in regions orthologous to B31 gene b31_0524 (Additional file 4: Figure S1), which has suffered various deletions/insertions in the different species. It is possible that these chromosomal indel differences could be used for species identification.

The linear chromosomes of four members of the relapsing fever Borrelia clade have also been sequenced, those of B. recurrentis, B. duttonii, B. hermsii and B. turicatae ([64]; S. Porcella et al., unpublished Genbank accession nos. CP000048 and CP000049). In regions of homology, their chromosomes are typically about $20 \%$ different in sequence from the Lyme agent species, and form three subgroups: recurrentis/duttonii, hermsii and turicatae within which hermsii and turicatae chromosomes are 5-10\% different and they in turn are 10-15\% different from recurrentis and duttonii (from our analysis of a number of randomly chosen sequences scattered across the chromosomes; see also $[46,65])$. The relapsing fever clade chromosomes are generally syntenic with the 
Table 2 Comparison of B. burgdorferi sensu lato chromosomes

\begin{tabular}{|c|c|c|c|c|c|c|c|c|c|c|c|c|c|c|c|c|c|c|c|c|c|}
\hline \multirow[b]{2}{*}{ Isolate } & \multicolumn{12}{|c|}{ B. burgdorferi } & \multirow{2}{*}{$\begin{array}{l}\text { B. "finlandensis" } \\
\text { SV1 }\end{array}$} & \multirow{2}{*}{$\begin{array}{l}\text { B. bissettii } \\
\text { DN127 }\end{array}$} & \multicolumn{2}{|c|}{ B. afzelii } & \multirow{2}{*}{$\begin{array}{l}\text { B. spielmanii } \\
\text { A14S }\end{array}$} & \multirow{2}{*}{$\begin{array}{l}\text { B. "bavariensis" } \\
\text { PBi }\end{array}$} & \multicolumn{2}{|c|}{ B. garinii } & \multirow{2}{*}{$\begin{array}{l}\text { B. valaisiana } \\
\text { vs116 }\end{array}$} \\
\hline & ZS7 & Bol26 & $64 b$ & JD1 & 156a & $118 a$ & $72 a$ & CA-11.2A & $94 a$ & W191-23 & N40 & 29805 & & & ACA-1 & Pko & & & Far04 & $\mathrm{PBr}$ & \\
\hline B31 & 0.309 & 0.298 & 0.259 & 0.469 & 0.488 & 0.511 & 0.515 & 0.506 & 0.525 & 0.519 & 0.572 & 0.553 & 1.719 & 5.051 & 7.114 & 7.117 & 7.671 & 7.230 & 7.262 & 7.221 & 7.299 \\
\hline ZS7 & & 0.084 & 0.321 & 0.522 & 0.515 & 0.549 & 0.551 & 0.554 & 0.578 & 0.541 & 0.599 & 0.582 & 1.750 & 5.070 & 7.076 & 7.079 & 7.657 & 7.228 & 7.260 & 7.219 & 7.301 \\
\hline Bol26 & & & 0.312 & 0.512 & 0.504 & 0.540 & 0.541 & 0.541 & 0.566 & 0.533 & 0.586 & 0.571 & 1.751 & 5.068 & 7.080 & 7.082 & 7.658 & 7.227 & 7.262 & 7.220 & 7.299 \\
\hline $64 \mathrm{~b}$ & & & & 0.471 & 0.488 & 0.498 & 0.501 & 0.504 & 0.515 & 0.512 & 0.575 & 0.577 & 1.720 & 5.052 & 7.112 & 7.115 & 7.670 & 7.240 & 7.266 & 7.224 & 7.299 \\
\hline JD1 & & & & & 0.447 & 0.467 & 0.465 & 0.477 & 0.471 & 0.522 & 0.608 & 0.602 & 1.729 & 5.053 & 7.121 & 7.122 & 7.677 & 7.237 & 7.269 & 7.222 & 7.311 \\
\hline 156a & & & & & & 0.428 & 0.433 & 0.489 & 0.490 & 0.498 & 0.563 & 0.560 & 1.700 & 5.040 & 7.108 & 7.110 & 7.668 & 7.222 & 7.254 & 7.209 & 7.290 \\
\hline 118a & & & & & & & 0.140 & 0.273 & 0.427 & 0.482 & 0.587 & 0.588 & 1.725 & 5.051 & 7.110 & 7.113 & 7.666 & 7.224 & 7.258 & 7.216 & 7.303 \\
\hline 72a & & & & & & & & 0.262 & 0.417 & 0.473 & 0.591 & 0.595 & 1.732 & 5.051 & 7.113 & 7.115 & 7.670 & 7.229 & 7.262 & 7.218 & 7.301 \\
\hline CA-11.2A & & & & & & & & & 0.437 & 0.479 & 0.584 & 0.593 & 1.729 & 5.053 & 7.114 & 7.116 & 7.678 & 7.231 & 7.260 & 7.220 & 7.308 \\
\hline 94a & & & & & & & & & & 0.529 & 0.591 & 0.625 & 1.746 & 5.065 & 7.130 & 7.131 & 7.678 & 7.242 & 7.273 & 7.230 & 7.317 \\
\hline W191-23 & & & & & & & & & & & 0.526 & 0.544 & 1.740 & 5.056 & 7.123 & 7.126 & 7.666 & 7.233 & 7.260 & 7.217 & 7.302 \\
\hline N40 & & & & & & & & & & & & 0.480 & 1.773 & 5.075 & 7.127 & 7.130 & 7.677 & 7.231 & 7.268 & 7.223 & 7.312 \\
\hline 29805 & & & & & & & & & & & & & 1.777 & 5.082 & 7.132 & 7.135 & 7.687 & 7.238 & 7.268 & 7.224 & 7.310 \\
\hline sV1 & & & & & & & & & & & & & & 5.100 & 7.148 & 7.155 & 7.716 & 7.267 & 7.297 & 7.260 & 7.337 \\
\hline DN127 & & & & & & & & & & & & & & & 7.423 & 7.430 & 7.986 & 7.621 & 7.568 & 7.539 & 7.621 \\
\hline ACA-1 & & & & & & & & & & & & & & & & 0.231 & 5.347 & 6.396 & 6.464 & 6.440 & 6.639 \\
\hline Pko & & & & & & & & & & & & & & & & & 5.350 & 6.401 & 6.470 & 6.444 & 6.631 \\
\hline A14S & & & & & & & & & & & & & & & & & & 7.096 & 7.116 & 7.095 & 7.252 \\
\hline PBi & & & & & & & & & & & & & & & & & & & 2.240 & 2.207 & 6.758 \\
\hline Far04 & & & & & & & & & & & & & & & & & & & & 0.800 & 6.739 \\
\hline $\mathrm{PBr}$ & & & & & & & & & & & & & & & & & & & & & 6.707 \\
\hline
\end{tabular}

a Table values are percent differences in nucleotide sequence as determined from pairwise comparisons of the Mugsy alignment described in the Methods section. 
Lyme agent chromosomes, but $B$. recurrentis and $B$. duttonii have about thirty gene content differences in the chromosomal "constant region" [64] (such an analysis has not been reported for $B$. hermsii and B. turicatae). It is clear that all known Borrelias have quite similar chromosomes.

\section{Borrelia plasmid diversity}

Among the 14 B. burgdorferi s.s. isolates analyzed, the number of plasmids carried by each strain varies between 12 (strain CA-11.2A) and 21 (strains B31 and WI91-23) (Table 1). The other B. burgdorferi s.l. species carry on average somewhat fewer plasmids, between 7 in $B$. garinii Far04 and 17 plasmids in B. afzelii PKo (Table 1). We have previously argued that plasmid proteins encoded by paralogous family (PFam) 32 correlate with the compatibility type of Borrelia plasmids that are $>10 \mathrm{kbp}$ in length $[57,59,63]$. Our preliminary unpublished analysis suggests that the sequenced Lyme agent plasmids represent 29 PFam32 protein compatibility types, and probably several additional types that do not have PFam32 genes. Since B31 carries 19 different PFam32 type plasmids, and only ten "new" types are present in the 21 subsequently sequenced genomes, it seems likely that if other plasmid compatibility types remain to be discovered, they are not common. Analysis of all 23 Lyme agent genomes shows that plasmids cp26, lp54 and at least a few cp32s are always present and largely structurally conserved (with the single exception of $B$. garinii strain Far04 which has no cp32 plasmid). Some plasmids, lp5 and lp21, are less common and present in fewer than $10 \%$ of the analyzed isolates, while other plasmids are nearly always present but are organizationally variable (lp17, lp25, lp28-1, -2, -3, -4, -5, -6, -7, -8 and -9, lp36, lp38, lp56). We recently described an in-depth analysis of the plasmids present in four B. burgdorferi s.s. isolates $[57,59,63]$, and a similar analysis of the additional plasmids sequenced in this study will be presented in a subsequent publication. Only the most highly conserved plasmids, cp26 and lp54, will be discussed further here.

\section{Single nucleotide polymorphism (SNP) analysis}

To further resolve the population structure of Borrelia species and gain insights into the evolutionary history, gene sequence conservation and diversity across Borrelia isolates, we applied a single nucleotide polymorphism (SNP)-based genotyping methodology on the predicted gene sequences that are conserved across all sequenced Borrelia linear chromosomes and the lp54 and cp26 plasmids, using the B. burgdorferi B31 genome as reference. Only intragenic SNPs were considered, because the goal was to gain insights into protein sequence variations across the different isolates (Table 1). The small number of SNPs that might be present in the gaps between contigs in the chromosomes that remain in "draft" state would not be included in our analysis, but this does not affect any of the conclusions drawn below.

We identified a total of 10,299 synonymous SNPs (sSNPs) and 7,007 non-synonymous SNPs (nsSNPs) in cp26, 14,703 sSNPs and 13,514 nsSNPs in lp54, and 342,892 sSNPs and 178,324 nsSNPs in the chromosomes of the 22 isolates [66]. The SNP locations were concatenated into one sequence and a maximum-likelihood phylogenetic tree was built with this information (Figure 2). The branching orders of the different species are identical in the chromosome and cp26 SNP trees, indicating that these two replicons as a whole have not been reassorted during the evolution of the strains in this study. All three SNP trees are consistent with the previously delineated B. burgdorferi s.l. species, since the different species reside on strongly-supported, well-separated branches. All three trees show that B. "finlandensis" (isolate SV1) is a rather close relative of B. burgdorferi (Figure 2). Nonetheless SV1 is consistently and robustly separated from the B. burgdorferi s.s. strain cluster as well as from the other species, confirming the uniqueness of the SV1 isolate and its status as a potential new species [53]. The trees also show that $B$. bissettii strain DN127 is most closely related to $B$. burgdorferi s.s., B. "bavariensis" $\mathrm{PBi}$ is most closely related to B. garinii, and B. spielmanii A14S is most closely related to $B$. afzelii. B. valaisiana VS116 not particularly closely related to any of the other species in this study. The lp54 SNP tree is quite similar to the chromosome and cp26 trees (Figure 2C), except that the B. garinii-B. "bavariensis" cluster occupies a somewhat different position in the tree that is less closely associated with the B. afzelii-B. spielmanii branch than in the other two trees, and the $B$. bissettii lp54 plasmid is more divergent than its chromosome or cp26. The positions of the B31 and WI91-23 lp54s are also somewhat different within the B. burgdorferi s.s. cluster than in the other two trees. lp54, while not appearing to have diverged more rapidly than the chromosome or cp26, may have undergone horizontal exchange at more locations than the other two replicons [66].

This SNP-based phylogeny reveals a tight grouping of all the B. burgdorferi s.s. strains, a finding consistent with their overall sequence similarity (above) and previous analyses using rRNA IGS sequences $[35,37]$ or protein-coding gene sequences in MLST analyses (Figure 1 and [33]). In addition, the chromosome and cp26 SNP trees (Figure 2A and $\mathrm{B})$ give very similar well-resolved pictures of the phylogenetic organization of the B. burgdorferi s.s. clade. The three SNP-based trees have highly supported branch points and consistently identify four subgroups: strains B31/64b/Bol26/ZS7, strains N40/29805/WI91-23, strains 118a/72a/CA11.2A-94a, and strains 156a/297/JD1. These four subgroups are named SNP groups A, B, C and D, respectively, in Figure 2. Intra-species chromosomal 


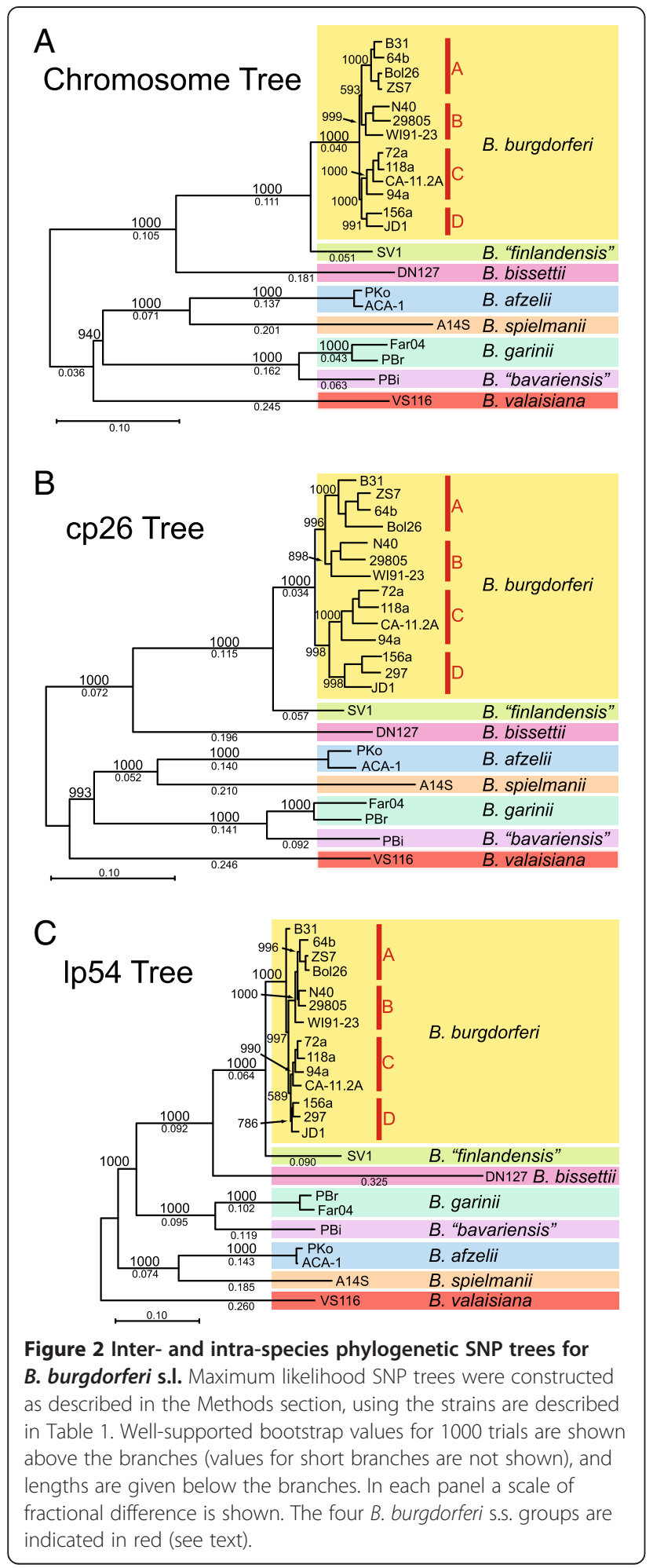

diversity is about the same in the three cases where multiple genome sequences are available from a single species; i.e., the 12 chromosomes of $B$. burgdorferi isolates are about as divergent from one another as the two $B$. garinii and the two $B$. afzelii isolates are from each other (see also Figure 2).

Are these four SNP-based B. burgdorferi s.s. chromosome and cp26 SNP subgroups consistent with other chromosomal typing methods? The previous chromosomal typing strategies to which we can compare our genome sequence data are rRNA IGS1 sequence type [35,37], rRNA IGS1 restriction site type (RST) [67,68] and two MLST schemes: the MLST analysis of Margos et al. [33] (as applied by Travinsky et al. [38]) and our MLST analysis (Figure 1). Both MLST studies included information from a number of chromosomal genes and so incorporate more information than the IGS1 categorizations; they utilized different sets of eight and six chromosomal genes, respectively. Table 3 shows a compilation of the chromosomal "types" determined by these different methods, and it shows that SNP group A is convincingly supported by all four of the above analyses. These four strains clearly represent a separate chromosomal clade from the rest of the B. burgdorferi s.s. isolates. IGS1 and MLST analyses indicate that IGS1 types

Table 3 B. burgdorferi chromosomal groups

\begin{tabular}{lllllllll}
\hline $\begin{array}{l}\text { Typing } \\
\text { Method }\end{array}$ & 1 & 2 & 3 & 4 & 5 & 6 & 7 & 8 \\
Strain & & & & & & & & \\
B31 & 1 & 1 & 1 & 1 & 1 & 1 & $1 / 2$ & A \\
64b & $3^{\mathrm{b}}$ & 1 & 1 & 1 & 1 & 1 & $1 / 2$ & $\mathrm{~A}$ \\
Bol26 & 1 & - & 3 & 1 & 1 & 1 & $1 / 2$ & $\mathrm{~A}$ \\
ZS7 & 1 & 1 & 3 & 1 & 1 & 1 & $1 / 2$ & $\mathrm{~A}$ \\
$\mathbf{1 5 6 a}$ & 2 & 2 & 2 & 2 & 2 & $2 \mathrm{a}$ & $2 / 1$ & $\mathrm{D}$ \\
$\mathbf{2 9 7}$ & 2 & 2 & - & 2 & 2 & $2 \mathrm{~b}$ & - & $\mathrm{D}$ \\
JD1 & 5 & 1 & 6 & 3 & 2 & $2 \mathrm{C}$ & $2 / 1$ & $\mathrm{D}$ \\
$\mathbf{7 2 a}$ & 4 & 2 & 4 & 3 & 3 & $3 \mathrm{a}$ & $1 / 1$ & $\mathrm{C}$ \\
$\mathbf{9 4 a}$ & $8^{\mathrm{b}}$ & 3 & 4 & 3 & 3 & $3 \mathrm{a}$ & $1 / 1$ & $\mathrm{C}$ \\
$\mathbf{1 1 8 a}$ & 5 & 2 & 4 & 3 & 3 & $3 \mathrm{~b}$ & $1 / 1$ & $\mathrm{C}$ \\
CA-11.2A & 5 & 2 & 2 & 3 & 3 & $3 \mathrm{a}$ & $1 /-$ & $\mathrm{C}$ \\
N40 & 9 & 3 & 5 & 3 & 4 & 4 & $2 / 2$ & $\mathrm{~B}$ \\
W191-23 & 7 & 2 & 4 & 3 & 5 & 4 & $2 / 1$ & $\mathrm{~B}$ \\
$\mathbf{2 9 8 0 5}$ & 6 & 3 & 7 & 3 & 6 & 4 & $1 / 1$ & $\mathrm{~B}$ \\
\hline
\end{tabular}

a. Chromosomal typing methods are as follows:

1. Ribosomal rRNA spacer IGS1 [35,37].

2. Arbitrary MLST group name [33,38].

3. Arbitrary MLST group name (Figure 1 this report).

4. RST type deduced from our sequences $[67,68]$.

5. Plasmid content similarity, arbitrary group name (S. Casjens, unpublished). 6. Chromosomal right end organization, arbitrary group name (S. Casjens, unpublished).

7. Two chromosomal indels: $157 \mathrm{bp}$ in gene 0021 and $27-30$ bp between genes 0001 and 0002 ( 1 = no deletion; $2=$ deletion).

8. Chromosomal, cp26 and Ip54 SNP type, this report.

- not determined.

b. IGS1 lineages 1 and 3 form a coherent superlineage, and IGS1 8 is a rather close relative of lineage IGS1 5 [35].

c. 297 chromosomal SNP type not determined. 
1 and 3 form one major chromosomal clade and all the other types form a second major division (Figure 1 and [35]). Dissection of the second major IGS1/MLST division into convincing sub-clades has been less certain. The inclusion of strains 156a and 297 in SNP group D is in agreement with rRNA and MLST analyses that also show these two strains to be closely related, however only the SNP analysis includes JD1 in this cluster. SNP groups $\mathrm{B}$ and $\mathrm{C}$ together correspond largely to RST type 3 , and some of these strains are similarly clustered by the other methods (e.g., IGS1 groups 94a, 118a and CA11.2A together; the Travinsky et al. [38] MLST groups 72a, 118a and CA-11.2A together; and our MLST groups 94a and 118a together). However, there are also significant differences among the different grouping methods. For example, both MLST analyses place 118a and WI9123 in the same group, while they robustly reside in SNP groups $\mathrm{C}$ and $\mathrm{B}$, respectively; and JD1 is placed in a different group in each of these three analyses. Thus, although all three SNP, IGS1 and MLST typing methods display the genetic diversity of B. burgdorferi species, significant differences exist among these analyses, even when the two MLST analyses are compared. These differences are most likely due to the relatively small number of polymorphic sites at IGS1 and MLST loci, which subject the latter trees more strongly to the homoplastic effects of recombination.

In Table 3 we also show a summary of the following three additional categorizations which are not subject to homoplasy issues: (i) Linear plasmid contents indicate that these are most similar within the following three groups: B31/64b/Bol26/ZS7, 156a/297/JD1, and 118a/72a/CA11.2A/94a (our analysis to be published elsewhere) which correspond perfectly to SNP groups A, D and C, respectively; (ii) the plasmid accretion events at the chromosome's right end are fully consistent with the four SNP groups (our analysis to be published elsewhere); and (iii) the $157 \mathrm{bp}$ deletion in chromosomal gene b31_0021 that is present in some $B$. burgdorferi s.s. strains (Additional file 3: Table S3) is limited to SNP groups B and D (both B type genomes have the deletion and two of the three group D chromosomes carry it). The fact that B type strain 29805 does not have the deletion, along with the facts that the linear plasmids of the three type B isolates are not particularly similar to each other or the other isolates and that the D strains are not clustered by IGS1 or MLST methods (the only exception to the latter is that N40 and 29805 are closely related to each other in the Travinsky et al. [38] MLST analysis), suggest that SNP group B strains may be less uniform than the other three SNP groups. The overall agreement between SNP analysis and the plasmid content, chromosome right end structure and deletions in homologues of gene 0021, along with the extremely large number of alleles in the SNP analysis, lead us to conclude that the SNP groups most accurately reflect the real average evolutionary history of the chromosome. Of course, occasional horizontal exchange of approximately gene sized DNA fragments is known to happen and can lead to differences in the evolutionary histories of any given locus [66].

\section{The Borrelia pan-genome}

The genetic repertoire of a given species can be much larger than the gene content of individual strains, as the gene content of individual strains of the same species can vary considerably, and new genes continue to be discovered even after sequencing the genomes of many isolates. This observation has led Tettelin and colleagues to introduce the concept of "pan-genome", defined as the sum of the core genome (genes shared by all strains) and the dispensable genome (genes absent from one or more strains, and genes that are unique to each strain) [69-71]. The core genome typically comprises the genes that encode essential functions related to the basic biology of the species, whereas the dispensable genome contributes to species' diversity and provides functions that are not essential to its basic lifestyle but that may confer selective advantages (niche adaptation, antibiotic resistance, ability to colonize new hosts, etc.). In order to understand the basic biology and population genetics of any species, the core and dispensable genomes must be known.

One approach to estimate the extent of the core and dispensable genome components is to compute the number of new genes identified each time a new genome of a species is sequenced. Each of the core and dispensable genomes should approach their true values as more genomes are analyzed, assuming the isolates chosen for sequencing span the genomic diversity of the species. This strategy was applied here for B. burgdorferi s.s. isolates (Figure 3), as well as B. burgdorferi s.l. isolates (Figure 4). Pan-genome calculations have not been previously applied to Borrelia due to the lack of high-quality complete genome sequence information.

\section{The $B$. burgdorferi sensu stricto pan-genome}

Comparative genome analysis performed with 13 B. burgdorferi s.s. genomes (Table 1) provides a picture of the genetic diversity within this species. Extrapolation of the exponential decay model shown in Figure 3A suggests that the size of the conserved gene core for the B. burgdorferi species reaches an asymptote with the comparison of $\sim 20$ $B$. burgdorferi genomes, for a number of core genes of $\sim 1250$ genes (dashed line in Figure 3A). The model is based on the median number of conserved genes in each of the permutations of all possible genome comparisons. The functions encoded by the conserved core genome closely follow the distribution profile of the functional 

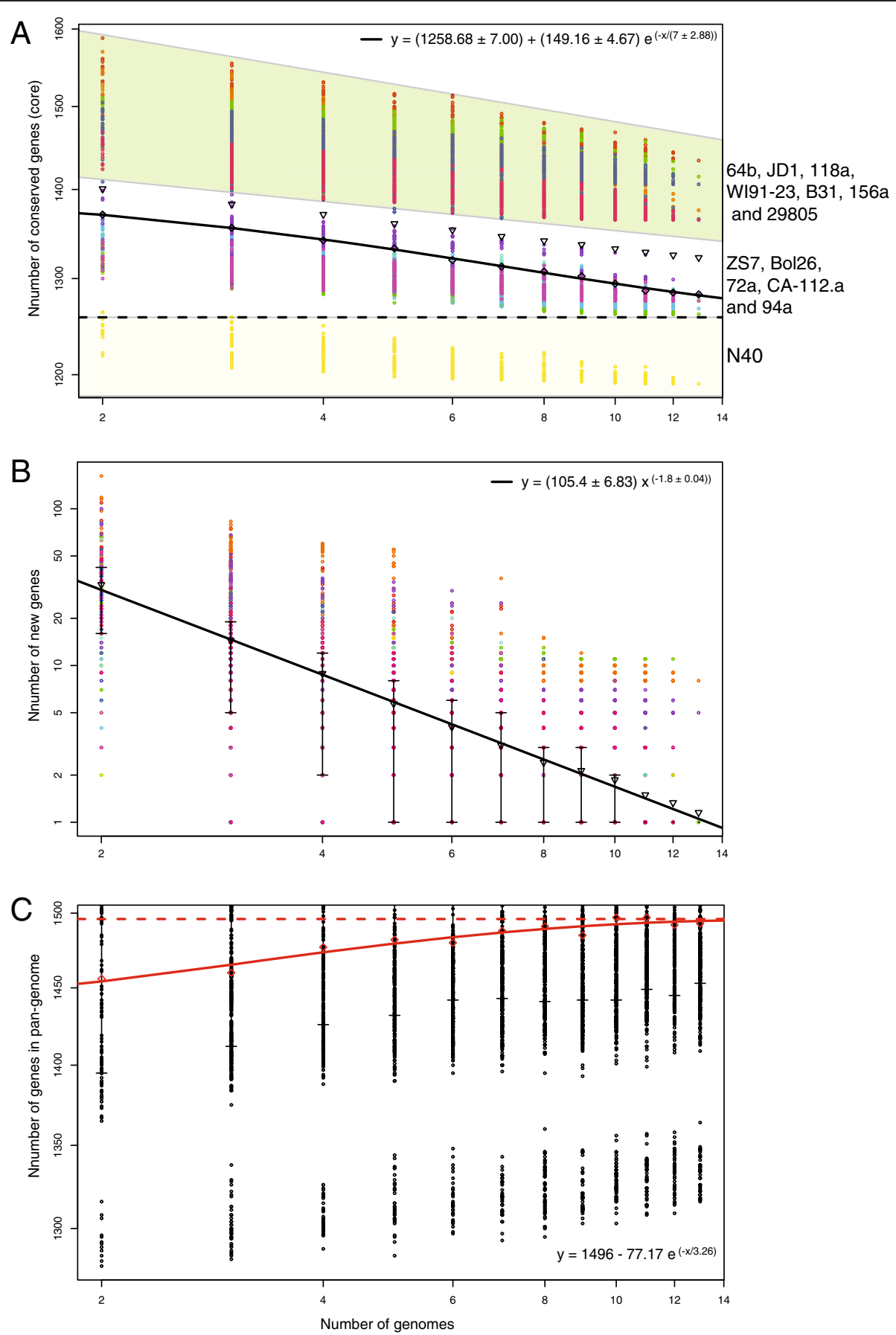

Figure 3 Pan-genome calculations of the conserved core, predicted new genes and pan-genome size of thirteen B. burgdorferi s.s. isolates. (A) Conserved genes (core genome) plotted as a function of the number $n$ of sequenced genomes ( $x$-axis). For each $n$, colored data point represents values of the number of conserved genes obtained for all possible combinations of compared genomes. The black line shows the exponential decay model based on the median value for conserved genes when increasing numbers of genomes are compared. (B) Plot showing decreasing numbers of discovered new genes with increasing number of genomes compared. The black line shows the exponential decay model based on the median value for new genes when increasing numbers of genomes are compared. (C) Pan-genome of the $B$. burgdorferi species. The extrapolated curve plateaus at a value of about 1500 with 13 genome sequences, and as a consequence, B. burgdorferi s.s. has a closed pan-genome. 

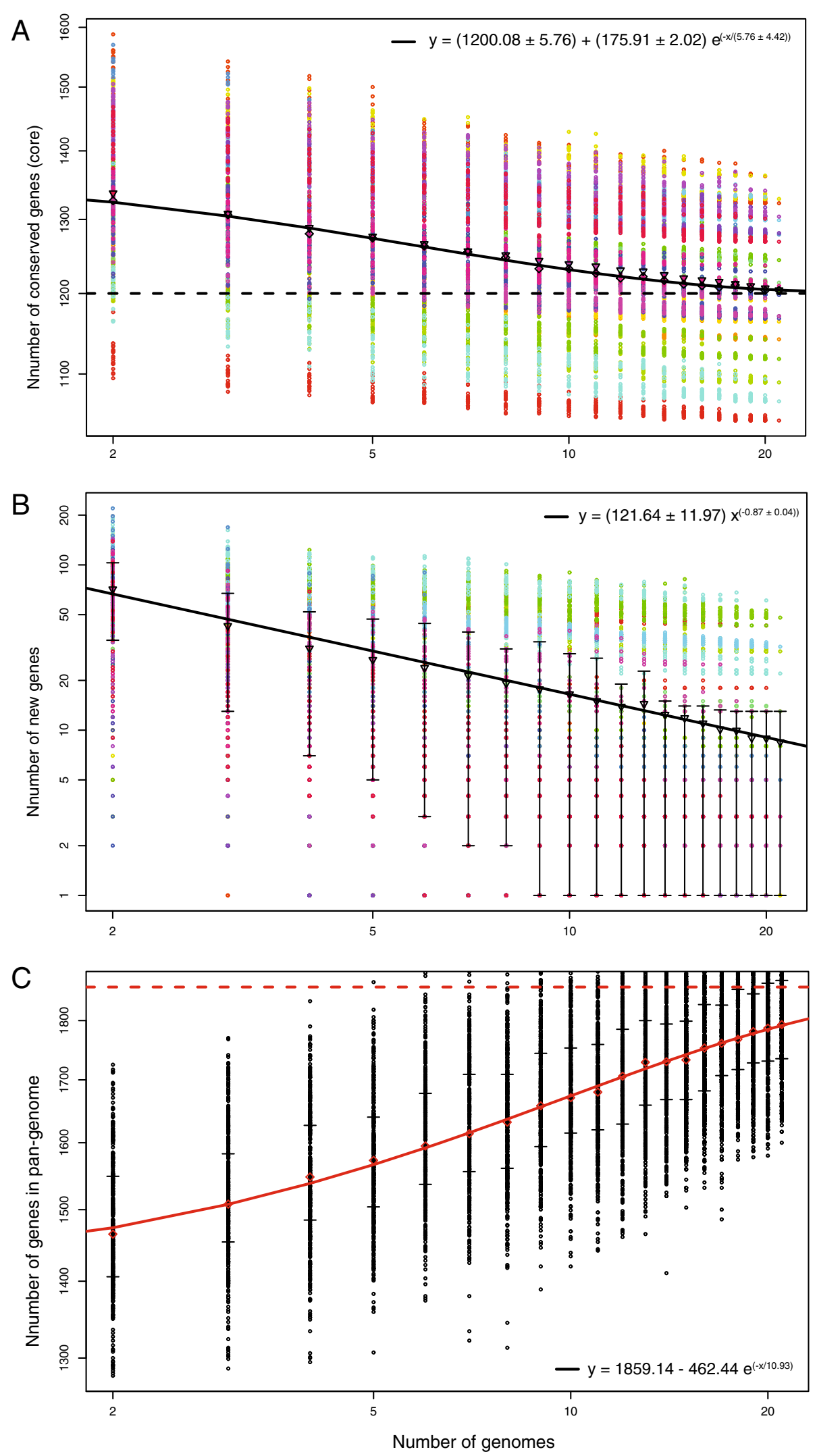

Figure 4 (See legend on next page.) 
(See figure on previous page.)

Figure 4 Pan-genome calculations of the conserved core, predicted new genes and pan-genome size of 21 B. burgdorferi s.s. and s.l. isolates. The pan-genome calculations displayed in the figure were performed in order to gain insight about the entire genomic diversity of the B. burgdorferi s.l. group. (A), Each colored data point represents values of the number of conserved genes calculated for different combinations of $n$ compared genomes ( $n$ value plotted on the $x$-axis). The exponential decay model (black solid line), based on the median value for conserved genes when increasing numbers of genomes are compared, predicts a conserved gene core for Borrelia sp. of 1200 genes. (B) Plot showing decreasing numbers of predicted new genes with increasing number of genomes compared. The black line shows the exponential decay model based on the median value for new genes when increasing numbers of genomes were compared. (C) The extrapolated curve plateaus at a value of 1859 genes, that is reached for a total of 21 genomes, highlighting the fact that there is some genomic diversity left to be discovered in $B$. burgdorferi s.l. isolates.

categories encoded in the entire Borrelia genome; e.g. there is no enrichment for a particular functional category in the set of conserved core genes. A total of $30.9 \%$ of the conserved core genes are hypothetical proteins (no sequence similarity outside of Borrelia and no predicted protein domains and motifs), highlighting the potentially important roles of these unknown genes in the Borrelia physiology.

Closer examination of the conserved core genes plot reveals 3 clusters of data points (Figure 3A). The first group of points, the yellow circles below the line $y=1258$ (Figure 3A), represent the genome comparisons in which the N40 strain is used as the reference. The size of the N40 core genome, compared to the other B. burgdorferi isolates, is approximately 1194 genes. The data points highlighted by the green area in Figure 3A, represent the genome comparisons where 7 strains are used as reference in permutations of genome comparisons: B31, 118a, 156a, 29805, 64b, JD1 and WI91-23. This group of strains is characterized by a larger core genome $(>1350$ genes). Finally, the third group of points is represented by the following 5 isolates: ZS7, Bol26, 72a, CA-112.a and $94 \mathrm{a}$ (1350 genes > core genome size > 1194 genes).

A likely explanation for the observation that permutations in which N40 is used as the reference genome lead to low values of predicted conserved gene core (Figure $3 \mathrm{~A}$ ) is that the $\mathrm{N} 40$ genome has a lower gene redundancy when compared to the other B. burgdorferi genomes. In order to test this hypothesis, we performed a Jaccard Orthologous Clustering (JOC) analysis on 21 Borrelia s.l. genomes. JOC analysis is typically used to group together highly similar proteins within a single genome/organism of interest and allows for 1-to-many orthology. JOC analysis has been applied to the analysis of various organisms such as Streptococcus pneumoniae [72], Neisseria meningitidis [73] and Plasmodium [72]. The Jaccard clustering analysis predicted a total of 1,479 orthologous protein clusters, each containing between 1 to 239 proteins (all genomes combined) (Additional file 5: Table S4). The protein cluster with the largest number of members, 239 proteins across all the genomes, has no known function and is encoded on the cp32 plasmids (a representative protein is b31_l02 which has been speculated to be a virion morphogenesis gene on the cp32 prophage plasmids $[57,74,75])$. On average, for the 100 orthologous protein clusters with the most members (representing a total of 7930 proteins across the 22 genomes included in the analysis), N40 had clusters with $26.2 \%$ fewer members than the equivalent clusters in strain B31 (Additional file 5: Table S4). This result confirms that the N40 genome has the lowest gene redundancy, in part contributing to the N40 smaller gene core.

Our pan-genome analysis also estimated the size of the dispensable genome of $B$. burgdorferi s.s., i.e. the genes absent from one or more strains and the genes that are unique to each strain (Figure 3B). The large deviation from the mean shown in Figure 3B, ranging from only a few to over one hundred genes, is a reflection of the genetic variation within $B$. burgdorferi. The regression model in Figure $3 \mathrm{~B}$ shows a rapid decrease in the predicted number of new genes discovered for each new B. burgdorferi genome sequenced. This number reaches 0 for a number of genomes close to 14 (regression crossing the $\mathrm{X}$-axis in Figure 3B), confirming that the 13 B. burgdorferi genomes included in our study should nearly cover the complete genetic diversity of the species and that the sequencing of additional strains (unless they came from a currently undiscovered clade) would add only marginally to the known genetic pool.

The pan-genome plot in Figure $3 \mathrm{C}$ represents an estimation of the complete Borrelia s.s. gene pool based on the set of genomes analyzed. The extrapolated curve ceases to increase as new genomes are added to the analysis and reaches a plateau of approximately 1500 genes: thus, the B. burgdorferi s.s. pan-genome is a "closed" pan-genome.

The pan-genome of $\boldsymbol{B}$. burgdorferi sensu lato species Because of their conserved synteny and highly related sequences, we also applied the pan-genome analysis to the $B$. burgdorferi s.l. group of species, including B. valaisiana, B. afzelii, B. garinii, B. bissettii and B. spielmanii. Calculation of the conserved core genome size predicted approximately 1200 core genes across 21 B. burgdorferi s.l. genomes (Figure 4A). The exponential decay shown in Figure $4 \mathrm{~A}$ is based on the median number of genes for each genome comparison, and reaches an asymptote with the comparison of about 20 genomes. The range of size of 
the core genomes is broad, and varies depending on the combination of genomes being compared, from 1,046 genes for strain Far04 (red dots at the bottom of the plot in Figure 4A) to 1,329 genes for strain JD1. The strains with the largest core genomes are JD1 (1,329 genes), 64b (1,323 genes), and 118a (1,304 genes). The strains with the smallest core genomes are Far04 (1,046 genes), PBr (1,068 genes), A14S (1,090 genes) and N40 (1,142 genes). Examination of the protein clusters from the JOC analysis (Additional file 5: Table S4) showed that only 1,003 orthologous protein clusters were identified in the genome of strain Far04 (the smallest of the genomes analyzed here), compared to a total of 1,081 for strain B31. The lower number of protein clusters predicted for stain Far04, reflecting the absence of proteins otherwise present in the other Borrelia s.l. genomes, is the main contributing factor explaining the Far04 smaller conserved core.

With 21 genomes compared, the predicted median number of new genes discovered per genome sequenced is 12 genes (Figure 4B). This suggests that there is still some genomic diversity left undiscovered within the Borrelia s.l. species although it may not be great. However, this predicted number of new genes is not homogenous and varies quite significantly depending on the genome considered, as highlighted by the wide variability in the data points in Figure 4B. The pan-genome analysis identified 48 unique genes in VS116, 52 for strain DN127, 30 for strains A14S and 22 for strain $\mathrm{PBr}$. In comparison, no unique genes were predicted for strains 64b, 118a, B31, 156a, Bol26, ZS7, 72a, CA-11.2a and N40 when compared to the other 20 genomes, confirming the results from the pan-genome analysis of the B. burgdorferi s.s. strains.

The pan-genome analyses we describe here might help predicting the genomic basis of human pathogenicity in $B$. burgdorferi s.l. For example, we identified genes uniquely present or absent in the genomes of $B$. burgdorferi s.s., B. afzelii, and B. garinii, the three species causing the majority of known cases of Lyme borreliosis. Three uncharacterized B31 plasmid genes (e0040, d0031, and f06) are present in all B. burgdorferi s.s. genomes while being absent in all other species including its closest outgroup SV1. The two B. afzelii genomes (PKo and ACA-1) have no uniquely present genes and one uniquely absent gene (far04_0259, uncharacterized). The two B. garinii genomes ( $\mathrm{PBr}$ and Far04) contain 69 uniquely present genes, one of which is predicted to be an adenine-specific DNA methyltransferase (far04_e0022). Intriguingly, a large number of Erp (ospE-related protein) genes are missing in $B$. garinii genomes. The relatively large number of uniquely gained and lost genes may be a result of adaptation of B. garinii to its avian reservoir hosts [47]. Lineage-specific genes in these three highly pathogenic species, most of which are encoded in the plasmids, are listed in Additional file 6: Table S5. Each of the three species was represented by at least two genomes, further strengthening the predictions of presence or absence of specific genes in the different Borrelia lineages. While these genes are strong candidates contributing to human virulence, there are also possibilities of neutral gene acquisition or loss.

The $B$. burgdorferi s.l. pan-genome size calculation (Figure 4C) suggests that the pan-genome of this group is open, e.g. the extrapolated curve continues to increase as new genomes get added to the analysis.

\section{Phylogeny-based pan-genome analysis}

Traditional pan-genome analysis, as applied above, uses the number of genomes as the sole explanatory variable. In some cases, this approach insufficiently captures variations in the pan-genome because of the underlining phylogenetic structure among the genomes. Phylogenetic autocorrelation among individual strains is common even in bacterial species with moderate amount of recombination such as E. coli and B. burgdorferi $[66,76]$. Except in an idealized population where individual genomes are equally related to each other (i.e., a "star phylogeny"), sampling an increasing number of genomes lead to an early plateau of the pan-genome size since random sampling quickly exhausts the total amount of phylogenetic diversity (Figure 5A, black line).

Pan-genome predictions could be improved by taking into account the phylogenetic relatedness of the genomes. A coalescence-based approach to pan-genome prediction has previously been applied to Streptococcus pneumoniae [77], and it has been shown that the linear dependence of pan-genome size on level of polymorphisms can be readily interpreted by the coalescence process [77]. In the present analysis, we used the length of the sub-tree connecting the genomes as a proxy for the total coalescence time among a set of genomes, an approach validated by the strong linearity of the relationships (Figure 5B). A molecular phylogenetic tree theoretically reflects gene coalescence history closely when there is no recombination between strains. Here, the level of recombination appears not high enough to distort genome phylogenies due to the fact that these trees are based on a large number of SNPs (Figure 2).

The coalescence model, and its extension to evolution between populations, requires a single explanatory parameter, the rate of gene acquisition $\omega$. This model removes the phylogenetic autocorrelation in nonlinear models, and assumes that the bacterial pan-genome is mainly dependent on the total tree distance between the genomes compared. Thus, any new genome added to the analysis can theoretically increase the pan-genome size proportionally to its contribution to the total genome tree. In the coalescence model, there is therefore no 

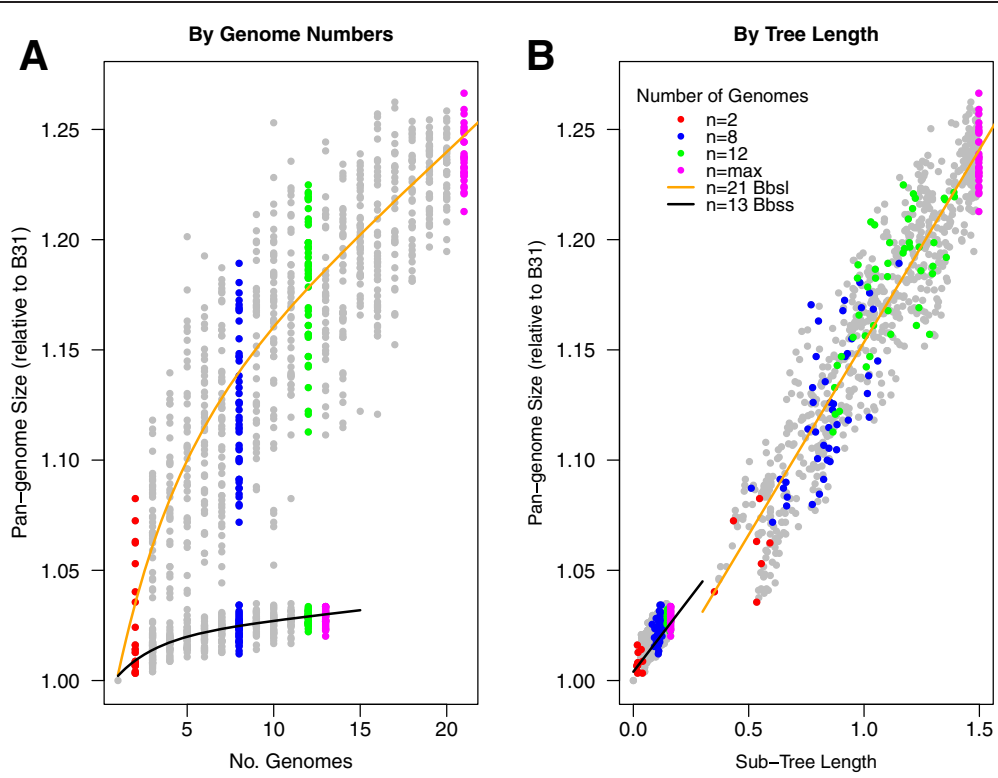

Figure 5 Phylogenetic correlation of B. burgdorferi s.I. and B. burgdorferi s.s pan-genomes. (A) Pan-genome sizes, calculated in permutations where the B31 genome is used as reference, are plotted against the number $n$ of genomes in the comparisons. Data points were fitted with negative exponential growth models (see Methods) [69]. The least-square fitted model for B. burgdorferi s.l. (solid orange line) takes the following parameter values (and respective standard errors): $\mathrm{D}=0.995(0.0121), \operatorname{tg}(\theta)=0.00725(0.00083), \mathrm{K}=0.0445(0.0187)$, and $\mathrm{T}_{n}=3.47(1.06)$. The model fit has an $\mathrm{R}^{2}=0.7479$. The model for B. burgdorferi s.s. (solid black line) has the following parameter values (and respective standard errors): $D=1.001(0.00276), \operatorname{tg}(\theta)=0.000917(0.00027), K=0.01446(0.0088)$, and $\tau_{n}=2.287(0.857)$. The model fit has an $R^{2}=0.6065$. (B) The same pan-genome calculations were fitted linearly with the sub-tree length of genomes in comparison, according to the neutral coalescence model: $\Omega_{n}=\Omega_{0}+\omega T_{n}$, where $\omega$ is the rate of gene acquisition [77]. The linear model for B. burgdorferi s.l. has $\Omega_{0}=1458$ (3.8) and $\omega=260.3$ (3.5) with a greatly improved $R^{2}=0.8762$ ( $\left.p<2 e-16\right)$. The linear model for $B$. burgdorferi s.s. has $\Omega_{0}=1501(0.91)$ and $\omega=202.3(0.05)$ with a slightly improved $R^{2}=0.6126(p<2 e-16)$. The improvement is due to a tighter fit of predicted pan-genome sizes with the tree lengths, in which some groups of genomes are more phylogenetically diverse (thus having larger pan-genome sizes) than others albeit the total number of genomes in comparison remain the same (e.g. comparing $n=8$, in blue, in the two panels).

concept of an "open" or "closed" pan-genome, as defined using previous strategies [71], but instead, the upper limit of a species pan-genome is solely determined by its overall phylogenetic diversity. Considering that the selection of bacterial isolates for genome sequencing is generally not random, the coalescence model might prove more robust in predicting bacterial pan-genomes. The coalescence model validates our genome sequencing strategy to sequence major evolutionary lineages within and between $B$. burgdorferi s.l. species, which maximizes pan-genome coverage for a given number of genomes.

Based on the coalescence model, expanding the set of genomes by sequencing additional $B$. burgdorferi s.s. lineages or B. burgdorferi s.l. species would extend the curves but not change the linear models themselves. According to the linear dependency of pan-genome sizes on the chromosomal SNP tree (Figure 2A), we estimate that the rates of gene acquisition within and between species are, respectively, $202.3 \pm 0.05$ and $260.3 \pm 3.5$ genes per unit tree distance, which is one substitution per nucleotide site on the main chromosome (Figure 5). The gene acquisition rate is thus $30 \%$ higher for between- species divergence than for within-species divergence. Since B. burgdorferi s.l. species may differ in vertebrate host preference but not necessarily in their tick vectors, one contributing factor to the accelerated gene acquisition between species could be host adaptation.

Considering the genetic distances (Table 2) for a pair of $B$. burgdorferi s.s. strains - about $0.50 \%$ per nucleotide site and a pair of B. burgdorferi s.l. species - 7.0\%, the above gene-acquisition rates translate to a gain of roughly $1.0(=202.3 \times 0.005)$ novel gene during strain divergence within species and 18 (=260.3 X 0.07) genes between species. Based on the length of the aligned common sequences of the main chromosomes ( $\mathrm{L}=843,710$ bases), these gene-acquisition rates translate to $2.4 \times 10^{-4}(=202.3 /$ L) SNPs within B. burgdorferi s.s. and $3.1 \times 10^{-4}(=260.3 / \mathrm{L})$ genes per SNP between $B$. burgdorferi s.l. Both rates are two orders of magnitude lower than the reported gene acquisition rate of $0.017 \pm 0.002$ genes per SNP in Streptococcus pneumonia [78]. These low gene-acquisition rates suggest that our previous conclusion of the gene-content stability of $B$. burgdorferi s.s. holds true for the entire $B$. burgdorferi s.l. species group [55]. Indeed, B. burgdorferi s. l. appears to have one of the largest core genomes among 
bacterial pathogens, which amounts to $83.9 \%$ (=1258.58/ 1500 ) of the pan-genome within B. burgdorferi s.s. (Figure 3$)$ and $64.6 \%(=1200 / 1859)$ of the pan-genome $B$. burgdorferi s.l. (Figure 4). In comparison, the proportion of the core genome relative to the pan-genome ranges from $8.6 \%$ in Clostridium botulinum to $41.1 \%$ in Yersinia pestis by one survey [78] and from 44\% in Escherichia coli to $98 \%$ in Mycobacterium tuberculosis by a more recent account [79]. Genome stability in B. burgdorferi s.l. and others may be a reflection of low rates of horizontal gene transfer and, ultimately, narrow ecological niches of these bacterial species [79]. Based on the high degree of genome stability of B. burgdorferi s.l. and the large variations in the size of paralogous gene families among strains (Additional file 5: Table S4 and Additional file 6: Table S5), we conclude that adaptive genome evolution in B. burgdorferi s.l. is driven primarily by duplication and loss of genes (especially lipoprotein genes) and not by acquisition of new genes through horizontal gene transfer. Nevertheless, variations in gene regulatory sequences may contribute to the adaptive genome divergence in B. burgdorferi s.l. as well.

The phylogeny-based pan-genome models allow for a more accurate prediction of the pan-genome size, providing a robust guidance for future genome sequencing efforts in B. burgdorferi s.l. In Figure 6, the predicted pan-genome sizes, calculated from genome permutations in which B31 was used as the reference, are plotted against the total number of phylogenetic groups. The goal of this approach was to determine how the predicted B. burgdorferi s.l. pangenome size might be affected by sequencing additional phylogenetic groups. The addition of each species genome to $B$. burgdorferi s.l. increases the pan-genome size by approximately $50-100$ distinct genes (3-7\% of a 1500-gene genome; Figure 6A). Since the overall relationship is linear (Figure 6A), we predict based on this model that future sequencing of new B. burgdorferi s.l. species is likely to add similar numbers of new genes. By the same reasoning, this analysis predicts that sequencing an additional ospC-typed genomic group (including those from Europe; see Figure 1) would add little ( $\sim 10$ new genes, $<1 \%$ of a genome) to the pan-genome of B. burgdorferi s.s. (Figure $6 \mathrm{~B}$ ).

\section{ORF sequence variation in Borrelia spp}

To quantify evolutionary constraints on the amino acid variations at each ORF locus, we calculated maximum likelihood estimates of synonymous $\left(K_{S}\right)$ and nonsynonymous $\left(K_{A}\right)$ nucleotide substitution rates between B31 and the other s.s. and s.l. strains by using the PAML package [80] (individual values of $K_{A}, K_{S}$, and $K_{A} / K_{S}$ in Additional file 7: Table S6). Among the three replicons, ORFs on
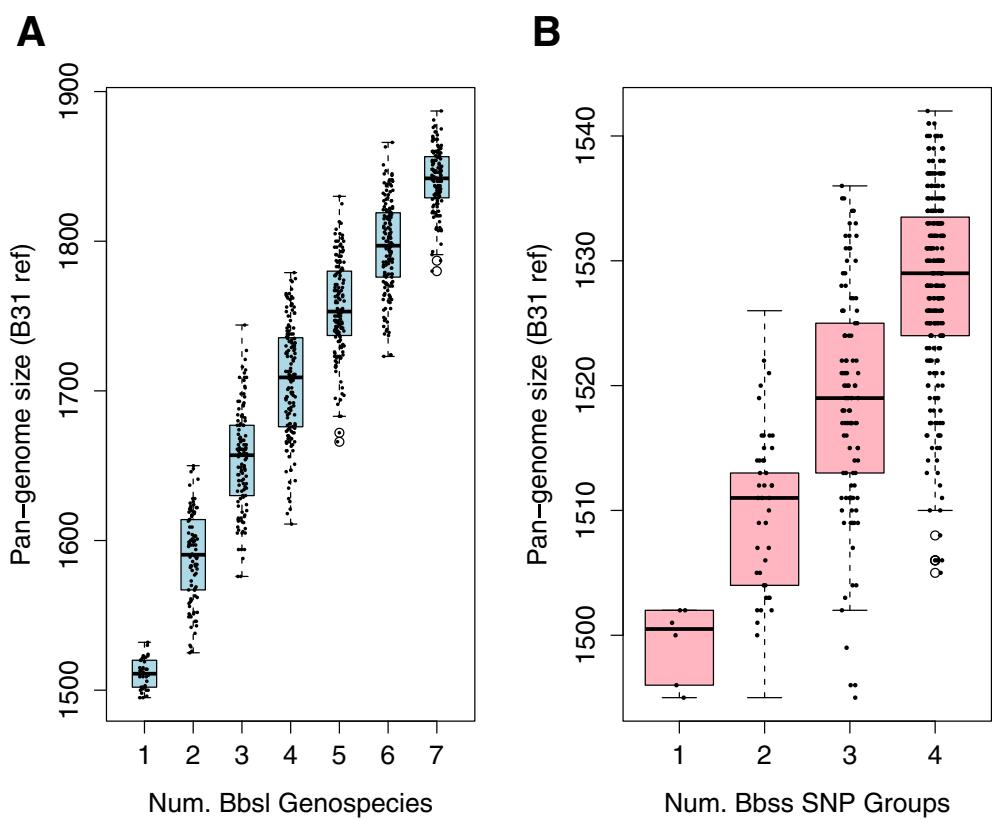

Figure 6 Phylogenetic prediction of future pan-genome growth. Using the same dataset as in Figure 4, the pan-genome sizes (y-axis) were re-plotted against the number of distinct phylogenetic groups ( $x$-axis) these genomes represent, another phylogeny-guided way to linearize the prediction of pan-genome sizes. (A) Each point represents the pan-genome size (y-axis) of a group of randomly selected genomes. The number of distinct B. burgdorferi s.l. species these genomes represent is plotted on $x$-axis. Based on the linearity of the median values, we estimate that sequencing an additional species would yield 100 new genes. (B) Each point represents the pan-genome size (y-axis) of a group of randomly selected genomes. The number of distinct B. burgdorferi s.s. SNP groups these genomes represent is plotted on $x$-axis. Predicted increase of the B. burgdorferi s.s. pan-genome with increasing number of SNP groups. Based on the linear median values, we estimate that sequencing an additional new SNP group (e.g., a European lineage) would yield merely $\sim 10$ new genes. 
Table 4 Synonymous and non-synonymous SNPs

\begin{tabular}{cccc}
\hline & cp26 & Ip54 & Chromosome \\
\hline No. of sSNPs & 10,299 & 14,703 & 342,892 \\
No. of nsSNPs & 7,007 & 13,514 & 178,324 \\
B31 vs. other $\boldsymbol{B}$. burgdorferi sensu stricto strains & \\
$\boldsymbol{K}_{\boldsymbol{A}}$ & $0.002302^{\mathrm{a}}$ & $0.001707^{\mathrm{b}}$ & 0.001033 \\
$\boldsymbol{K}_{\boldsymbol{S}}$ & $0.01924^{\mathrm{a}}$ & $0.006192^{\mathrm{b}}$ & 0.007981 \\
$\boldsymbol{K}_{\boldsymbol{A}} / \boldsymbol{K}_{\boldsymbol{S}}$ ratio & $0.120^{\mathrm{a}}$ & $0.276^{\mathrm{b}}$ & 0.129 \\
B31 vs. other $\boldsymbol{B}$. burgdorferi sensu lato strains & \\
$\boldsymbol{K}_{\boldsymbol{A}}$ & $0.0243^{\mathrm{a}}$ & $0.03530^{\mathrm{b}}$ & 0.01403 \\
$\boldsymbol{K}_{\boldsymbol{S}}$ & $0.2907^{\mathrm{a}}$ & $0.2309^{\mathrm{b}}$ & 0.1573 \\
$\boldsymbol{K}_{\boldsymbol{A}} / \boldsymbol{K}_{\boldsymbol{S}}$ ratio & $0.0837^{\mathrm{a}}$ & $0.153^{\mathrm{b}}$ & 0.0892 \\
\hline
\end{tabular}

${ }^{a}$ Mean value with ospC (b19) excluded

${ }^{b}$ Mean value with $d b p A$ (a24) excluded

cp26 have the highest average $K_{S}$ values $\left(p=10^{-6}\right.$ in a $t$-test of within-species $K_{S}$ values between cp26 and lp54; Table 4). The elevated $K_{S}$ values on cp26 are almost certainly a result of selectively maintained high localized recombination rates in regions surrounding osp $C$ [66]. ORFs on lp54 show significantly higher $K_{A} / K_{S}$ ratios than those on cp26 and the main chromosome for both the withinand between-species comparisons $\left(p=10^{-9}\right.$ in a $t$-test of within-species $K_{A} / K_{S}$ ratios between cp26 and lp54; Table 4). The relatively high $K_{A} / K_{S}$ ratios of ORFs on lp54 suggest a high level of adaptive amino-acid variations on this plasmid, an explanation consistent with the high proportion of genes encoding surface-localized lipoproteins on this plasmid including $o s p A, o s p B, d b p A, d b p B$, as well as the PFam54 array of CRASP-1-like genes $[57,63,81]$. On all three replicons, the within-species $K_{A} / K_{S}$ ratios are greater than the between-species $K_{A} / K_{S}$ ratios (Table 4), A higher level of amino-acid variations within- than betweenspecies may be a result of slightly deleterious mutations within bacterial populations [82]. It is also possibly due to the fact that some amino-acid variations (such as those at $\operatorname{ospC)}$ are beneficial and selectively maintained within B. burgdorferi s.s. populations. Further investigation (e.g., by simulations) is needed to evaluate these possibilities.

Two genes, $\operatorname{ssp} C$ and $d b p A$, were excluded from the above analysis because their $K_{A}$ and $K_{S}$ values were clearly outliers compared to other ORFs (Figure 7). These two genes are unique in having similar withinand between-species $K_{A}$ and $K_{S}$ values, a result consistent with the presence of strong balancing selection within B. burgdorferi populations [66]. These two genes are among the genes highly and exclusively expressed during host invasion [83-85]. To a much lesser extent the cp26 gene $b 08$, which encodes a putative lipoprotein [86], shows unusually high $K_{A}$ values in both withinspecies and between-species comparisons (Figure 7). Two genes on lp54, a07 (putative ChpAI protein) and a22 (hypothetical protein), showed high within-species
$K_{A}$ but normal $K_{A}$ and $K_{S}$ values in the between-species comparison. A large number of ORFs on lp54, most of which are predicted to encode lipoproteins, showed high $K_{A}$ values in between-species comparisons, including $a 65$ (a CRASP-1 family gene), a53 (function unknown), a33 (encodes a putative lipoprotein) and $a 54$ (function unknown) (Figure 7). It should be noted that 29 ORFs on lp54 (that include ORFs encoding DbpA and CRASP-1) are missing in the between-species comparisons, because of the many gaps in the sequence alignments due to high sequence divergence. Two ORFs on the main chromosome (0102 and 0404, both of unknown function) also showed high $K_{A}$ values in between-species comparisons. Since these genes have significantly high $K_{A}$ values within populations, between populations, or both, their amino acid variations may be adaptive. In contrast, three genes involved in plasmid partitioning on cp26 $(b 11, b 12$, and b13) showed unusually low $K_{A} / K_{S}$ ratios, suggesting a high degree of amino-acid sequence conservation (Figure 7).

\section{Adaptive genome radiation as population expands}

While evolutionarily stable, as B. burgdorferi s.l. populations expand its genomes are expected to diversify rapidly through sequence and copy-number variations at host-interacting loci such as $\operatorname{ssp} C$. Mathematical analysis showed that the mean coalescence time of $n$ segregating alleles at a locus under balancing selection is extended-relative to the neutral expectation-by a scaling factor: $E\left\{T_{n}\right\}=2 N_{e} f_{s}(1-1 / n)$ [EQ.1], where $N_{e}$ is the effective population size and $f_{s}$ is the scaling factor that increases with selection intensity [87]. The same analysis suggested rapid emergence of new alleles at such a locus as a population grows. For example, when selection is strong and the population size (after expansion) is large, the time for emergence of new alleles at such a locus in a diploid population is a small fraction of $2 \mathrm{~N}$ generations or, more precisely, in the order of $1 /(4 M S)$ [EQ.2], where $M=N_{e} \mu, S=2 N_{e} s, \mu$ is the mutation rate, and $s$ is the selection coefficient [87]. The time for the emergence of $r$ new alleles at the same locus is given by the formula $T_{r}=\frac{1}{2 M} \sum_{j=1}^{j=r} \frac{1-e^{-\frac{2 S}{j(j+1)}}}{1-e^{-\frac{S}{j N}}}$ [EQ.3] in the unit of $2 N_{e}$ [87]. To predict how the genomic diversity of the Lyme pathogen would be affected by the on-going population expansion of $B$. burgdorferi s.s. in North America $[88,89]$, we simulated genome evolution under a model of immune escape and frequent recombination (described in Methods) [66]. Consistent with the above theoretical expectations, the steady-state sequence diversity at immune-escape loci increases proportionally with the population size (Figure 8A) and the number of distinct genomic lineages increases correspondingly (Figure $8 \mathrm{~B}$ ). These theoretical and simulation analyses 


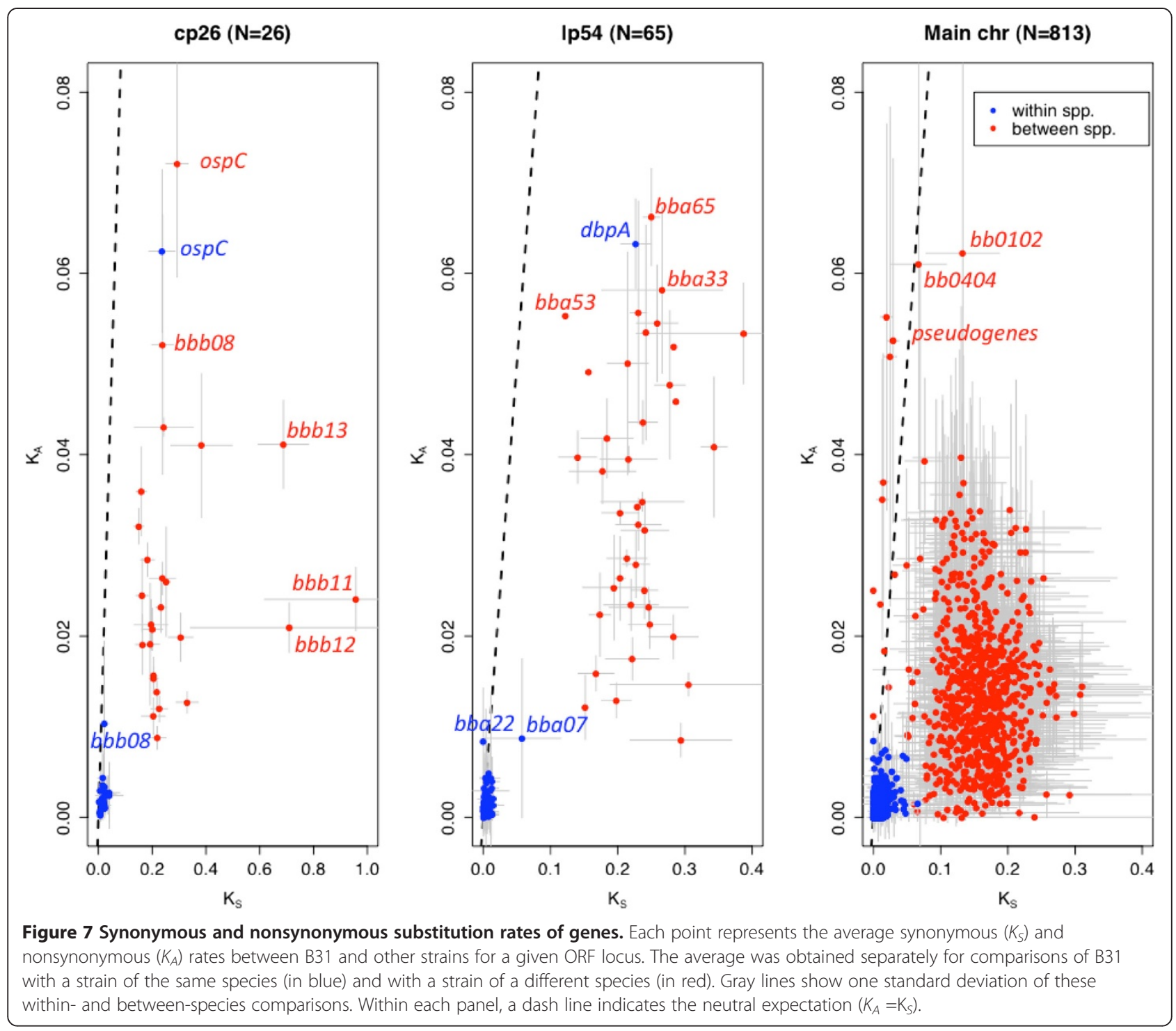

may be used to estimate key population-genetic parameters of the Lyme disease endemics such as the effective population size, time since colonization, and time for emergence of new genomic groups. For example, the mutation parameter of B. burgdorferi s.s. in Northeastern U.S. could be estimated from nucleotide diversity at the ribosomal RNA spacer (IGS) loci, because simulations on the effects of intra-genic recombination showed a gradual decay of $f_{s}$ towards one (i.e., neutral expectation) at loci with increasing distances from the selection target [90]. Since $M=2 N_{e} \mu_{0}=0.025$ at an IGS locus [34] and assuming a neutral mutation rate $\mu_{0}=1 \times 10^{-9}$, we obtained an estimate of $N_{e}=1.3 \times 10^{7}$ for B. burgdorferi s.s. in the Northeastern U.S. If the selective advantage of a new allele is $s=1 \times 10^{-3}$ at $o s p C$, then $S=N_{e} s=1.3 \times 10^{4}$. Considering that there are currently about $20 \operatorname{osp} C$ major alleles segregating in the Northeastern U.S., it could be estimated from EQ.3 that the time since its introduction from Europe is in about $0.5 N_{e}$ generations, which is fifty thousand years if we assume $B$. burgdorferi replicates 100 generations per year. The rise of the first new ospC allele would take about 300 years based on EQ.2. Both of these time estimates would be considerably shortened by taking into consideration the fact that the intragenic recombination rate is three times the mutation rate [49].

\section{Conclusions}

We have determined the genome sequences of $22 \mathrm{~B}$. burgdorferi s.l. isolates. This information was used to generate SNP trees of the chromosome and the most conserved plasmids cp26 and lp54. These trees robustly show phylogenetic relationships among these isolates both within and among different species. Our results show that B. burgdorferi s. s. and B. "finlandensis" form 

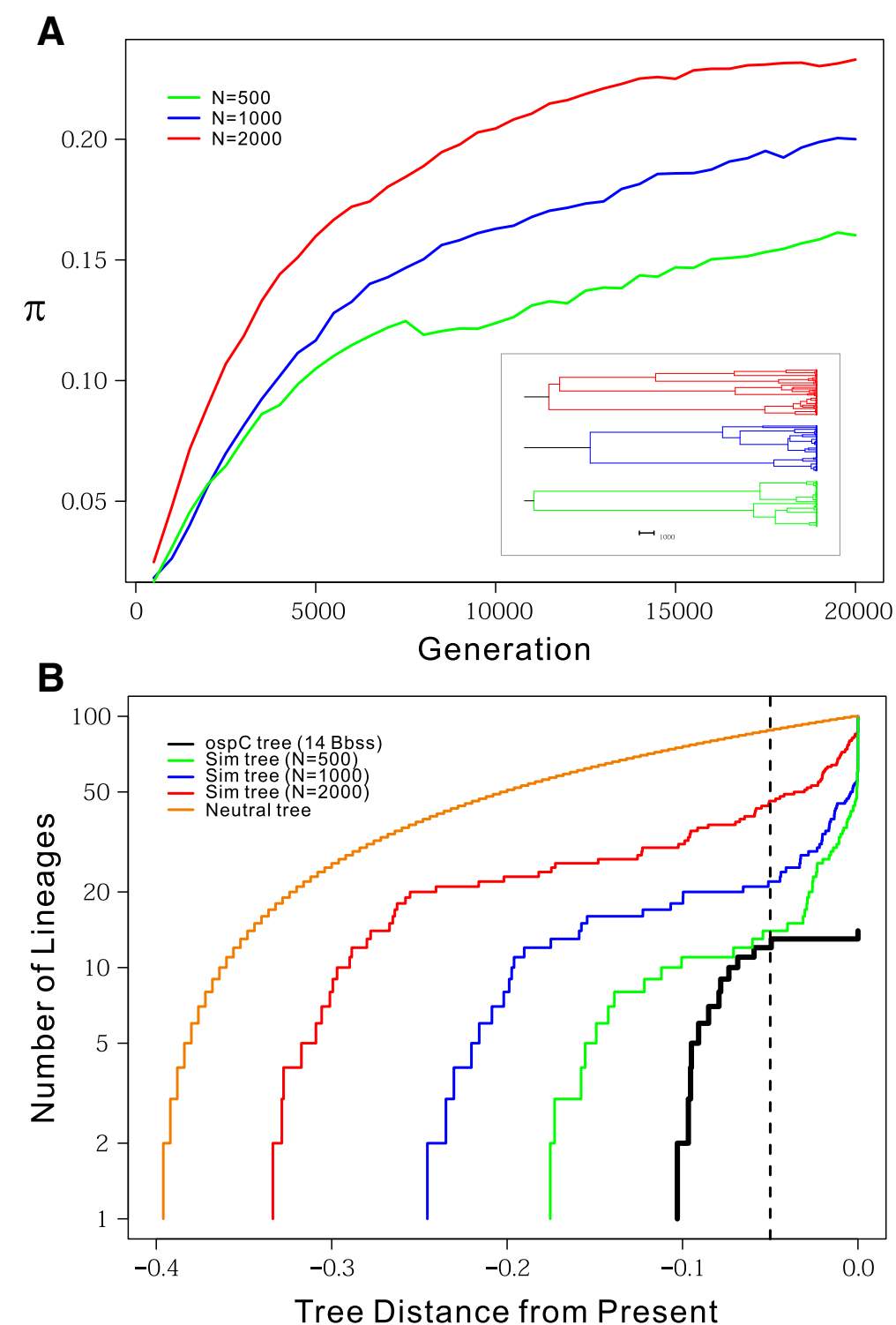

Figure 8 Predicted increase of genomic diversity with B. burgdorferi population expansion. We simulated evolution of three bacterial populations, each of which consisted of a constant size of $\mathrm{N}=500$ (in green), 1000 (in blue), or 2000 (in red) haploid genomes. One of the eight genes in the simulated genome evolves under immune-mediated negative frequency-dependent selection (FDS) as ospC is likely to be. Other genes were under purifying selection like housekeeping genes. (A) We measured nucleotide diversity at the FDS locus by sampling 100 individuals every 500 generations. Doubling of the population size results in a proportional increase in nucleotide diversity. (Inset) We reconstructed the coalescence trees for the last population samples. These trees show characteristics of balancing selection such as elongated internal branches and compressed terminal branches. (B) Lineage-Through-Time (LTT) plots of the tree based on ospC sequences from 14 B. burgdorferi s.s. genomes (in black), a simulated neutral coalescence tree (in orange), and trees of FDS sequences from simulated populations (in green, blue, and red). In comparison with the neutrally evolving genomes, the LTT plots of balanced gene trees show early rapid rise of gene lineages that are subsequently maintained for a long period of time, before the final rapid rise to the sample sizes.

a closely related group, as do B. garinii and $B$. "bavariensis". B. bissettii is rather closely related to B. burgdorferi s.s., but $B$. "finlandensis" is the closest known outgroup of B. burgdorferi s.s. B. afzelii and B. spielmanii form a robust (but less closely related) group, and B. valaisiana is not especially closely related to any of the other species analyzed here. These findings are largely in agreement with previous studies using only a few sequences from each isolate, but they provide a statistically much more robust and quantitative description of these relationships. We also find that, despite fairly frequent within-population recombination, the B. burgdorferi s.s. isolates fall into four wellsupported groups.

We conclude that the intra- and inter-specific pangenome sizes of $B$. burgdorferi s.l. depend strongly on its phylogenetic history. By taking phylogenetic relatedness 
among pathogen genomes into consideration, phylogenyguided pan-genome analysis removes sampling artifacts in traditional approaches based on genome numbers and yields robust predictions on the pan-genome sizes of pathogens as well as their rates of gene acquisition. $B$. burgdorferi s.l. has a highly stable genome, with one of the lowest gene-acquisition rates and one of the largest core genome among bacterial pathogens. Adaptive genome differentiation between and within B. burgdorferi s.l. species is driven mostly by copy-number and sequence variations rather than by gains and losses of lineage-specific virulence genes. Finally, we predict a rapid emergence of novel $o s p C$ groups in areas newly colonized by B. burgdorferi s.l. Due to a lack of molecular clock to calibrate the time scale of sequence evolution, however, it remains a challenge to estimate a time scale and the rate of such emergence of new genomic groups in local B. burgdorferi s.l. populations.

\section{Methods}

Provenance of the Borrelia isolates, propagation and DNA isolation

In order to select strains of B. burgdorferi s.s. with the highest level of genetic diversity, isolates were obtained from clinical and tick specimens and cultures from animals in the U.S. and Europe as previously described (Table 1) [34]. Spirochetes were cultivated at $34^{\circ} \mathrm{C}$ in complete BSK II medium (Sigma, St. Louis, Mo) and total genomic DNA was then isolated from $10 \mathrm{ml}$ of low passage log-phase bacteria after centrifugation at 10,000 rpm for $30 \mathrm{~min}$ at $4^{\circ} \mathrm{C}$. Pellets were washed twice with Tris-Cl buffer $(10 \mathrm{mM}$ Tris pH7.5, $100 \mathrm{mM} \mathrm{NaCl})$, and resuspended in $430 \mu \mathrm{l}$ TES $(10 \mathrm{mM}$ Tris pH7.5, $100 \mathrm{mM} \mathrm{NaCl}$, $10 \mathrm{mM}$ EDTA). Subsequently, $10 \mu \mathrm{l}$ of freshly prepared lysozyme $(50 \mathrm{mg} / \mathrm{ml}), 50 \mu \mathrm{l}$ Sarkosyl (10\%), and $10 \mu \mathrm{l}$ proteinase $\mathrm{K}(10 \mathrm{mg} / \mathrm{ml})$ were then added and the mixture was incubated at $50^{\circ} \mathrm{C}$ overnight prior to RNase treatment. Following incubation, DNA was extracted with phenol/ chloroform and chloroform, precipitated with ethanol, and finally resuspended in TE buffer $(1 \mathrm{mM}$ Tris pH7.5, 1 mM EDTA).

\section{Multilocus sequencing analysis (MLSA)}

PCR amplification followed by DNA sequencing across $64 B$. burgdorferi s.l. isolates was performed on 6 chromosomal housekeeping genes ( $g a p, a l r, g l p A, x y l B$, $a c k A, \operatorname{tgt}), \operatorname{osp} C$ and the IGS locus as previously described [34]. Sequences for these 6 housekeeping genes and the IGS locus were deposited to Genbank under the following accession numbers: gap, KC416567 - KC416611; alr, KC416477 - KC416521; glpA, KC416432 - KC416476; $x y l B, \mathrm{KC4} 16316$ - KC416360; ackA, KC416522 KC416566; tgt, KC416361 - KC416405; and rrs-rrlA, KC416406 - KC416431.
The 6 housekeeping genes and the IGS sequences were used to infer the overall within- and betweenspecies phylogeny among $B$. burgdorferi isolates $[37,41]$. Orthologous sequences from the Borrelia hermsii DAH genome (NCBI BioProject PRJNA29637) were collected for the purpose of rooting the MLST phylogenetic tree. The concatenated DNA sequences at the 7 loci were aligned using ClustalW [91]. Two approaches, a Bayesian method with codon sitespecific evolutionary rates using MrBayes [92] and the other maximum likelihood method with 100 bootstrapped alignments using DNAML in PHYLIP [93], were employed for phylogenetic reconstruction based on concatenated sequences. Branch supports were measured by the posterior probabilities in the Bayesian method and the bootstrap values in the maximum likelihood method. We selected 22 isolates representing major phylogenetic lineages for wholegenome sequencing to estimate the size and composition of the pan-genome of the B. burgdorferi s.l. species complex. Thirteen of these sequenced isolates represent major evolutionary lineages of B. burgdorferi sensu strico, a widely distributed pathogenic species causing Lyme disease across three continents (see below).

\section{Whole-genome shotgun sequencing: library construction, genome assembly and closure}

All the Borrelia strains included in this study were sequenced as previously described [94] by the random shotgun method using Sanger DNA sequencing to an estimated 8-fold coverage. Unless otherwise noted in Table 1, all the plasmids were sequenced to closure, while some sequencing and physical gaps were left in the chromosomes. Briefly, one small insert plasmid library $(2-3 \mathrm{~kb})$ and one medium insert plasmid library (7-8 kb) were constructed for each strain and sequenced to $\sim 5 \mathrm{X}$ and $3 \mathrm{X}$ coverage, respectively. Approximately 10,625 and 6,375 successful reads for the small and medium insert plasmid libraries were sequenced, representing a total of $\sim 14 \mathrm{Mb}$ of sequencing data for each strain. The sequences from the respective strains were assembled separately using a combination of the TIGR Assembler [95] and Celera Assembler [96]. All sequence and physical gaps in the plasmids were closed by editing the ends of sequence traces, primer walking or transposon-primed sequencing [97] on plasmid clones, and combinatorial PCR followed by sequencing of the PCR product. Pseudo-molecules for the draft sequences of the chromosomes and some of the plasmids (Table 1) were constructed using NUCmer [98] and BAMBUS $[94,99]$ as previously described [94]. 


\section{Genome annotation and open reading frame (ORF) nomenclature}

Genome annotation was performed using the JCVI Prokaryotic Annotation Pipeline (www.jcvi.org/cms/research/ projects/prokaryotic-annotation-pipeline/overview/).

Briefly, an initial set of open reading frames (ORFs) likely to encode proteins was identified by GLIMMER (http:// ccb.jhu.edu/software/glimmer/index.shtml). ORFs that overlapped were inspected visually and, in some cases, removed. ORFs were searched against an internal nonredundant protein database, PANDA (Protein and Nucleotide Data Archive) as described previously for all JCVI genomes. PANDA is JCVI's internal repository of non-redundant and non-identical protein and nucleotide data built periodically from public databases that include the latest protein sequences (e.g. GenBank (http:// www.ncbi.nlm.nih.gov), PDB (http://www.rcsb.org/pdb/ Welcome.do), UniProt (http://www.uniprot.org/) and the Comprehensive Microbial Resource database (http://www. tigr.org/CMR)). Two sets of hidden Markov models (HMMs) were used to determine ORF membership in families and superfamilies. These included 10,340 HMMs from PFAM version 23.0 (http://pfam.sanger.ac.uk/) and 3,603 HMMs from TIGRFam version 8.0 (www.jcvi.org/cms/research/projects/tigrfams/overview/). TOPPRED was used to identify membrane-spanning domains in proteins.

In an effort to improve the accuracy and consistency of the annotation of the chromosomal genes, curation of the JD1, N40 and 297 genome annotation was performed in parallel. The B31 genome annotation was also updated in the process. ORFs $\leq 50$ codons were not annotated, and those in the 51-100 range were not annotated unless they are intact in all three of the chromosome since the 297 chromosome sequence was not determined. Two chromosomal ORFs, B31_0771a and B31_0838a, were identified that were not recognized in the original annotation of the B31 chromosome. Including these comparisons in the analysis results in the annotation of significantly fewer short ORFs as potentially functional genes; many of those not included in the present analysis were previously suspected to be spurious gene identifications and not functional genes [57]. We thus identify 815 putative protein coding genes in the constant region of these chromosomes. These 815 putative genes as well as the tRNA, tmRNA and rRNA genes are all present and in identical locations in all B. burgdorferi chromosomes. Comparison of the predicted ORFs in the constant regions of the $B$. burgdorferi B31, N40 and JD1 chromosomes identified twenty ORFs in which one is disrupted by an in-frame stop or frameshift relative to the other two strains (Additonal file 1: Table S1). Some of these differences may be the result of sequencing errors; e.g., B31_0078 and 0079 are joined as one gene in Genbank Accession AF492471, and are now annotated as one gene in these four genomes.
Borrelia researchers have usually used the "locus tags" of the strain B31 genome GenBank annotation [57,86] as names for genes and their encoded proteins. Thus, according to bacterial convention, the B31 chromosomal genes have been named "bb0xxx" (lower case and italicized) in ascending order from $b b 0001$ upward across the chromosome. The B31 plasmid locus tag names are similar but have the form " $b b \$ x x$ " in which " $\$$ " is a letter code denoting which plasmid type carries the gene (e.g., a74 encodes protein A74 and lies on lp54, s09 lies on cp32-3, etc.). Increased genome sequencing forces the use of more complex locus tags. For example, BbuJD1_Axx for strain JD1 plasmid lp54 with its letter code of A. We suggest the use the form "strain name_locus tag letter and/or number only" for gene names when it is important to delineate their strain source (e.g., B31_0843 for a B31 chromosomal gene, and "JD1_\$\#\#" for a JD1 plasmid gene with plasmid letter code). In the different genomes, the same locus tag numbers in the chromosome, cp26 and lp54 usually indicate orthology of the corresponding genes; however, organizational differences in the other plasmids made this system unworkable so the same locus tag numbers on these replicons do not indicate orthology.

\section{Whole-chromosome phylogenetic analysis and percent identity calculations}

The chromosomal sequences from 26 Borrelia sp. were aligned with Mugsy [100], which incorporates MUMmer $[98,101]$ and SeqAn [102]. Mugsy performs fast multiple alignments of closely-related whole genomes without requiring a reference sequence. It is robust in identifying a rich complement of genetic variation including duplications, rearrangements, and large-scale gain and loss of sequence. The Mugsy computes produced an output composed of blocks of conserved, aligned sequences between species in a MAF file format. Blocks were then joined together and converted to a multifasta file with the bx-python toolkit (http://bitbucket.org/james_taylor/bx-python/wiki/Home). The resulting alignment of twenty-two Borrelia burgdorferi s.l. chromosomal conserved blocks of sequence was 906,966 bp long including small indels. This alignment was further processed, and columns with gaps in any one genome were removed, resulting in an 843,710 bp chromosomal core sequence alignment. Considering that the common region of the Borrelia chromosome is about $903 \mathrm{kp}$ long, our chromosome core sequence alignment incorporates $95.4 \%$ of the potential genetic information of the chromosomes, and it provides a fast and accurate estimate of the substitution differences that have accumulated between the unambiguously homologous sequences that are present in all of the genomes being compared.

An approximately-maximum-likelihood phylogenetic tree (Jukes-Cantor + CAT model) was subsequently 
inferred from the final Mugsy alignment using FastTree2 [103] with one thousand bootstrap replicates and a generalized time-reversible model. The Mugsy alignment was also used to calculate the percentages of nucleotide similarities and differences between the chromosomal blocks of conserved core sequences, using the infoalign program from the EMBOSS software analysis package [104].

Core genes, gene discovery and pan-genome computations Core-genome and pan-genome calculations were performed as previously described by Tettelin and colleagues [69]. Briefly, estimations of core genes, new genes, and pan-genome size were performed using all-versus-all WU-BLASTP and all-versus-all WU-TBLASTN searches according to W. Gish (http://blast.wustl.edu) [105]. The results from these two sets of searches were combined such that the TBLASTN searches prevented missing gene annotations from producing false negatives. Sequence gaps in the draft chromosomes (Table 1) were sufficiently small that they contained few, if any, chromosomal genes. Hits were filtered such that homologues were defined as having $50 \%$ sequence similarity over at least $50 \%$ of the length of the protein. The determination of core genes and strainspecific genes depends on the number of genomes included in the analysis. The number $(\mathrm{N})$ of independent measurements of the core and strain-specific genes present in the $\mathrm{n}^{\text {th }}$ genome is $\mathrm{N}=\mathrm{S} /((\mathrm{n}-1) ! \cdot(\mathrm{S}-\mathrm{n}) !)$, where $\mathrm{S}$ is 13 (B. burgdorferi s.s. ) and 21 (B. burgdorferi + other Borrelia species). A random sampling of 1000 measurements for each value of $\mathrm{n}$ was calculated to reduce the number of required computations. The numbers of core and strain-specific genes for a large number of sequenced isolates were extrapolated by fitting the exponential decaying functions $F_{c}(n)=\kappa_{c} \exp \left(-n / \mathrm{\tau}_{c}\right)+\operatorname{tg}_{c}(\theta)$ and $F_{n}(n)=\kappa_{n}$ $\exp \left(-n / \tau_{n}\right)+\operatorname{tg}_{n}(\theta)$, respectively, to the mean number of conserved and strain-specific genes calculated for all strain combinations. $n$ is the number of sequenced strains, and $\kappa_{c}, \tau_{c}, \kappa_{n}, \tau_{n}, \operatorname{tg}_{c}(\theta)$, and $\operatorname{tg}_{n}(\theta)$ are free parameters. $\operatorname{tg}_{c}(\theta)$ and $\operatorname{tg}_{n}(\theta)$ represent the extrapolated number of core and strain-specific genes, assuming a consistent sampling mechanism and a large number of completed sequences. The pan-genome itself represents an estimation of the complete gene pool based on the set of genomes analyzed and was computed in triplicates. In this case, a sample of at most 1,000 combinations for each value of $n$ was taken and the total number of genes, both shared and strain specific, was calculated. A power law regression was then fitted to estimate the total number of genes accessible to the subsets of tested genomes or the pan-genome, using the median values at each $n$. The least-squared model fitting was performed using the "nls" (Nonlinear Least Squares) function in R (www.r-project.org/).

Regression of the pan-genome size against the total tree length allows for an estimation of the rate of gene acquisition: $\Omega_{n}=\Omega_{0}+\omega T_{n}$, where $\omega$ is the rate of acquisition of new genes and $\Omega_{n}$ and $T_{n}$ are, respectively, the pan-genome size and the total tree length of $n$ sampled genomes [77]. We calculate the tree length of sampled genomes based on the chromosome SNP tree by using customized Perl scripts based on the BioPerl [106] programming library. We used the $\mathrm{R}$ statistical package for linear regression analysis.

\section{Jaccard Orthologous Clustering (JOC) analysis}

Jaccard orthologous clustering was used to cluster proteins from the different Borrelia genomes analyzed in this study, in order to identify orthologous genes. Jaccard clustering was performed using the Sybil software package [72,107], available at Sourceforge (http://sybil.sourceforge.net/) and implemented at the Institute for Genome Sciences using the Ergatis bioinformatics workflow [108]. The following parameters were used: Jaccard coefficient $=0.6$ and minimum BLASTP percent identity threshold $=80 \%$.

\section{Single-nucleotide polymorphism discovery and analysis}

Single-nucleotide polymorphisms were identified in pairwise genome comparisons between the predicted genes on the closed chromosome, as well as linear plasmid lp54 and circular plasmid cp26, of B. burgdorferi strain B31 and the corresponding chromosome and plasmids of 23 strains of Borrelia (see Table 1) using MUMmer [98]. We note that all of the other plasmids have suffered enough inter-plasmid recombination to make assignments of orthologs challenging and therefore were not included in this analysis. By mapping the position of the SNP to the annotation in the reference strain B31 genome, it was possible to determine the effect on the deduced polypeptide and classify each SNP as synonymous (sSNPs) or non-synonymous (nsSNPs). The SNP data set was curated to include only SNPs in MUMmer alignments with at least $70 \%$ identity. Positions within repeats and regions with greater than $5 \%$ gap characters were excluded from the analysis. All stop codons in the aligned sequences were identified, and the corresponding positions were removed from all sequences. sSNPs and nsSNPs for each Borrelia strain compared to the reference B31 were then concatenated to form "SNP pseudosequences", which were used to generate a phylogenetic tree using the HKY93 algorithm [109] with 500 bootstrap replicates. The Geneious software package (http://www.geneious.com) and SplitsTree4 (www. splitstree.org/) were used for visualization.

The Phylogenetic Analysis by Maximum Likelihood (PAML) programs package, and more specifically the codeml program, was used for $K_{A} / K_{S}$ analyses. To estimate a single $K_{A} / K_{S}$ ratio averaged over all lineages and all sites, the basic model of Goldman and Yang was used [110]. 


\section{Simulation of genome evolution}

We used SimBac (http://sourceforge.net/projects/bacsim/), a software package for simulating bacterial genome evolution, to predict the total number of genomic lineages in local B. burgdorferi s.s. populations [66]. These simulations allowed us to explore how deeply natural populations need to be sampled in order to fully account for their total genomic diversity, whether the genomic diversity is stable or increases over time, and how genomic diversity is influenced by recombination, natural selection, and population expansion. Briefly, the simulated bacterial population initially contained 1,000 identical genomes, each of which consisted of 6 protein-coding genes. In mimicking genome evolution driven by variations of major surface antigens (e.g., ospC), we designated one gene (the "FDS" locus) to be under the influence of positive natural selection, in which amino-acid replacement mutations were preferred in a negative-frequency-dependent fashion. Amino-acid replacement mutations at all other gene loci lowered the genome fitness, simulating housekeeping genes in a bacterial genome. We kept the population size constant and let the population evolve for 10,000 to 20,000 generations. During each none-overlapping generation, individual genomes were subject to random uniform mutations and gene conversion. The genetic structure of the population was characterized using average pairwise nucleotide differences $(\pi)$, coalescent tree, and the lineage-throughtime (LTT) plot. The LTT plot tracks the number of evolutionary lineages of a coalescence tree at regular time intervals and, thereby, helps to visualize the rate of lineage diversification over time [111]. The coalescence tree of a B. burgdorferi s.s. population under balancing selection is characterized by elongated internal branches and compressed terminal branches relative to a neutrally derived coalescence tree. Such long internal branches correspond to major evolutionary lineages in the population. Since long internal branches appear as a period of stasis on a LTT plot, we use the height of such stasis as an estimate of the total number of major lineages in a population. To explore the effect of sampling to estimation of genetic diversity, we sampled 100 individuals from the final stabilized population. To estimate the rate of increase of genetic diversity over time, we sampled 50 individuals every 500 generations. Lastly, we varied population size to predict the effect of population expansion to the genomic diversity in B. burgdorferi s.l. populations.

\section{Additional files}

Additional file 1: Table S1. B. burgdorferi s.S. chromosomal open reading frame differences.

Additional file 2: Table S2. B. burgdorferi s.s chromosomal indels $>25$ bp. Additional file 3: Table S3. Chromosome structural differences between B. burgdorferi B31 and B. afzelii PKo and ACA-1.
Additional file 4: Figure S1. B. burgdorferi sensu lato chromosomal differences in the gene 0522-0524 region. Translational six-reading frame diagrams are shown for the gene B31_0522-0527 region and homologs in other isolates. Translation is left to right in top three frames where the open reading frames are red, and right to left in bottom three, where the open reading frames are yellow. Genes with apparently broken open reading frames are indicated in green (it is not known if the B31_0522 frame is broken or if this represents a sequencing error). Long vertical lines in each frame represent stop codons and short vertical lines indicate methionine codons. Numbering of bps starts at the beginning of the grpE (519) gene.

Additional file 5: Table S4. Orthologous gene clusters. Each number in columns 3 through 24 represents the number of proteins for each genome for a given cluster.

Additional file 6: Table S5. Species-specific ORFs.

Additional file 7: Table S6. $K_{A}, K_{S_{1}}$ and $K_{A} / K_{S}$ values of individual ORFs for both within- and between-species comparisons.

\section{Abbreviations}

s.s.: Sensu stricto; s.l.: Sensu lato; Osp: Outer-surface protein; Pfam: Paralogous family; SNP: Single nucleotide polymorphism; MLST: Multi-locus sequence typing; JOC: Jaccard orthologous clustering.

\section{Competing interests}

The authors declare that they have no competing interests.

\section{Author's contributions}

Conceived and designed the experiments: EFM, BLL, SRC, WGQ, JJD, SES and CMF. Performed the experiments and genome analyses: EFM, WGQ, SRC, JFB, YX, EFD, DRR, BLC, PEP, YAH and LCV. Wrote the paper: EFM, WGQ and SRC. All authors read and approved the final manuscript.

\section{Acknowledgements}

This work was supported by grants Al49003, Al074825, Al37256, Al107955, Al47553 and N01-Al30071 from the National Institute of Allergy and Infectious Diseases (NIAID), and MD007599 (Hunter College) from the National Institute on Minority Health and Health Disparities (NIMHD) of the National Institutes of Health $(\mathrm{NIH})$. The content of this manuscript is solely the responsibility of the authors and do not necessarily represent the official views of NIAID, NIMHD, or NIH.

\section{Author details}

${ }^{1}$ Institute for Genome Sciences, University of Maryland School of Medicine, Baltimore, Maryland 21201, USA. ${ }^{2}$ Department of Pathology, Division of Microbiology and Immunology, University of Utah Medical School, Salt Lake City, Utah 84112, USA. ${ }^{3}$ Department of Medicine, Health Science Center, Stony Brook University, Stony Brook, New York 11794, USA. ${ }^{4}$ Department of Biological Sciences, Hunter College of the City University of New York, New York, New York 10065, USA. ${ }^{5}$ Biology Department, Brookhaven National Laboratory, Upton, New York 11793, USA. 'Department of Medicine, University of Medicine and Dentistry of New Jersey, New Jersey Medical School, Newark, New Jersey 07103, USA.

Received: 28 May 2013 Accepted: 26 September 2013

Published: 10 October 2013

\section{References}

1. Piesman J, Clark KL, Dolan MC, Happ CM, Burkot TR: Geographic survey of vector ticks (Ixodes scapularis and Ixodes pacificus) for infection with the Lyme disease spirochete, Borrelia burgdorferi. J Vector Ecol 1999, 24:91-98.

2. Steere AC, Coburn J, Glickstein L: The emergence of Lyme disease. J Clin Invest 2004, 113:1093-1101.

3. Radolf J, Salazar J, Dattwyler R: Lyme disease in humans. In Borrelia molecular biology, host interaction and pathogenicity. Edited by Samuels DS, Radolf J. Norfolk: Caister Academic Press; 2010:487-533.

4. Dennis DT, Nekomoto TS, Victor JC, Paul WS, Piesman J: Reported distribution of Ixodes scapularis and Ixodes pacificus (Acari: Ixodidae) in the United States. J Med Entomol 1998, 35:629-638. 
5. Ostfeld RS, Canham CD, Oggenfuss K, Winchcombe RJ, Keesing F: Climate, deer, rodents, and acorns as determinants of variation in lyme-disease risk. PLoS Biol 2006, 4:e145

6. Piesman J, Schwan TG: Ecology of Borreliae and their arthropod vectors In Borrelia molecular biology, host interaction and pathogenicity. Edited by Samuels DS, Radolf J. Norfolk: Caister Academic Press; 2010:251-276.

7. Brisson D, Dykhuizen DE: OspC diversity in Borrelia burgdorferi: different hosts are different niches. Genetics 2004, 168:713-722.

8. Hanincova K, Kurtenbach K, Diuk-Wasser M, Brei B, Fish D: Epidemic spread of Lyme borreliosis, northeastern United States. Emerg Infect Dis 2006, 12:604-611.

9. Rauter C, Hartung T: Prevalence of Borrelia burgdorferi sensu lato genospecies in Ixodes ricinus ticks in Europe: a metaanalysis. Appl Environ Microbiol 2005, 71:7203-7216.

10. Gern L, Estrada-Pena A, Frandsen F, Gray JS, Jaenson TG, Jongejan F, Kahl O, Korenberg E, Mehl R, Nuttall PA: European reservoir hosts of Borrelia burgdorferi sensu lato. Zentralbl Bakteriol 1998, 287:196-204.

11. Morens DM, Folkers GK, Fauci AS: Emerging infections: a perpetual challenge. Lancet Infect Dis 2008, 8:710-719.

12. Stanek G, Reiter M: The expanding Lyme Borrelia complex-clinical significance of genomic species? Clin Microbiol Infect 2011, 17:487-493.

13. Richter D, Schlee DB, Allgower R, Matuschka FR: Relationships of a novel Lyme disease spirochete, Borrelia spielmani sp. nov., with its hosts in Central Europe. Appl Environ Microbiol 2004, 70:6414-6419.

14. Glöckner G, Lehmann R, Romualdi A, Pradella S, Schulte-Spechtel U, Schilhabel M, Wilske B, Suhnel J, Platzer M: Comparative analysis of the Borrelia garinii genome. Nucleic Acids Res 2004, 32:6038-6046.

15. Johnson R, Schmid G, Hyde F, Steigerwalt A, Brener D: Borrelia burgdorferi sp. nov.: etiological agent of Lyme disease. Int J Syst Bacteriol 1984, 34:496-497.

16. Mathiesen DA, Oliver JH Jr, Kolbert CP, Tullson ED, Johnson BJ, Campbell GL, Mitchell PD, Reed KD, Telford SR 3rd, Anderson JF, et al: Genetic heterogeneity of Borrelia burgdorferi in the United States. J Infect Dis 1997, 175:98-107.

17. Postic D, Ras NM, Lane RS, Hendson M, Baranton G: Expanded diversity among Californian borrelia isolates and description of Borrelia bissettii sp. nov. (formerly Borrelia group DN127). J Clin Microbiol 1998, 36:3497-3504.

18. Margos G, Hojgaard A, Lane RS, Cornet M, Fingerle V, Rudenko N, Ogden N, Aanensen DM, Fish D, Piesman J: Multilocus sequence analysis of Borrelia bissettii strains from North America reveals a new Borrelia species, Borrelia kurtenbachii. Ticks Tick Borne Dis 2010, 1:151-158.

19. Baranton G, Postic D, Saint Girons I, Boerlin P, Piffaretti JC, Assous M, Grimont PA: Delineation of Borrelia burgdorferi sensu stricto, Borrelia garinii sp. nov., and group VS461 associated with Lyme borreliosis. Int J Syst Bacteriol 1992, 42:378-383.

20. Canica MM, Nato F, du Merle L, Mazie JC, Baranton G, Postic D: Monoclonal antibodies for identification of Borrelia afzelii sp. nov. associated with late cutaneous manifestations of Lyme borreliosis. Scand J Infect Dis 1993, 25:441-448.

21. Wang G, van Dam AP, Le Fleche A, Postic D, Peter O, Baranton G, de Boer R, Spanjaard L, Dankert J: Genetic and phenotypic analysis of Borrelia valaisiana sp. nov. (Borrelia genomic groups VS116 and M19). Int J Syst Bacteriol 1997, 47:926-932.

22. Masuzawa T: Terrestrial distribution of the Lyme borreliosis agent Borrelia burgdorferi sensu lato in East Asia. Jpn J Infect Dis 2004, 57:229-235.

23. Assous MV, Postic D, Paul G, Nevot P, Baranton G: Western blot analysis of sera from Lyme borreliosis patients according to the genomic species of the Borrelia strains used as antigens. Eur J Clin Microbiol Infect Dis 1993, 12:261-268.

24. Collares-Pereira M, Couceiro S, Franca I, Kurtenbach K, Schafer SM, Vitorino L, Goncalves L, Baptista S, Vieira ML, Cunha C: First isolation of Borrelia lusitaniae from a human patient. J Clin Microbio/ 2004, 42:1316-1318.

25. de Carvalho IL, Fonseca JE, Marques JG, Ullmann A, Hojgaard A, Zeidner N, Nuncio MS: Vasculitis-like syndrome associated with Borrelia lusitaniae infection. Clin Rheumatol 2008, 27:1587-1591.

26. Diza E, Papa A, Vezyri E, Tsounis S, Milonas I, Antoniadis A: Borrelia valaisiana in cerebrospinal fluid. Emerg Infect Dis 2004, 10:1692-1693

27. Fingerle V, Schulte-Spechtel UC, Ruzic-Sabljic E, Leonhard S, Hofmann H, Weber K, Pfister K, Strle F, Wilske B: Epidemiological aspects and molecular characterization of Borrelia burgdorferi s.l. from southern Germany with special respect to the new species Borrelia spielmanii sp. nov. Int J Med Microbiol 2008, Int J Med Microbiol (3-4):279-290.

28. Rijpkema SG, Tazelaar DJ, Molkenboer MJ, Noordhoek GT, Plantinga G, Schouls LM, Schellekens JF: Detection of Borrelia afzelii, Borrelia burgdorferi sensu stricto, Borrelia garinii and group VS116 by PCR in skin biopsies of patients with erythema migrans and acrodermatitis chronica atrophicans. Clin Microbiol Infect 1997, 3:109-116.

29. Rudenko N, Golovchenko M, Ruzek D, Piskunova N, Mallatova N, Grubhoffer L: Molecular detection of Borrelia bissettii DNA in serum samples from patients in the Czech Republic with suspected borreliosis. FEMS Microbiol Lett 2009, 292:274-281.

30. Foretz M, Postic D, Baranton G: Phylogenetic analysis of Borrelia burgdorferi sensu stricto by arbitrarily primed PCR and pulsed-field gel electrophoresis. Int J Syst Bacteriol 1997, 47:11-18.

31. Postic D, Ras NM, Lane RS, Humair P, Wittenbrink MM, Baranton G Common ancestry of Borrelia burgdorferi sensu lato strains from North America and Europe. J Clin Microbiol 1999, 37:3010-3012.

32. Ras N, Postic D, Baranton G: Borrelia burgdorferi sensu stricto, a bacterial species "Made in the U.S.A."? Int J Syst Bacteriol 1997, 47:1112-1117.

33. Margos G, Gatewood A, Aanensen D, Hanincova K, Terekova D, Vollmer S, Cornet M, Piesman J, Donaghy M, Bormane A, et al: MLST of housekeeping genes captures geographic population structure and suggests a European origin of Borrelia burgdorferi. Proc Natl Acad Sci USA 2008, 105:8730-8735.

34. Qiu WG, Bruno JF, McCaig WD, Xu Y, Livey I, Schriefer ME, Luft BJ: Wide distribution of a high-virulence Borrelia burgdorferi clone in Europe and North America. Emerg Infect Dis 2008, 14:1097-1104.

35. Attie O, Bruno JF, Xu Y, Qiu D, Luft BJ, Qiu WG: Co-evolution of the outer surface protein $C$ gene (ospC) and intraspecific lineages of Borrelia burgdorferi sensu stricto in the northeastern United States. Infect Genet Evol 2007, 7:1-12.

36. Barbour AG, Travinsky B: Evolution and distribution of the ospC Gene, a transferable serotype determinant of Borrelia burgdorferi. MBiO 2010, 1:e00153-10

37. Bunikis J, Garpmo U, Tsao J, Berglund J, Fish D, Barbour AG: Sequence typing reveals extensive strain diversity of the Lyme borreliosis agents Borrelia burgdorferi in North America and Borrelia afzelii in Europe. Microbiology 2004, 150:1741-1755.

38. Travinsky B, Bunikis J, Barbour AG: Geographic differences in genetic locus linkages for Borrelia burgdorferi. Emerg Infect Dis 2010, 16:1147-1150.

39. Jones KL, Glickstein LJ, Damle N, Sikand VK, McHugh G, Steere AC: Borrelia burgdorferi genetic markers and disseminated disease in patients with early Lyme disease. J Clin Microbiol 2006, 44:4407-4413.

40. Seinost G, Dykhuizen DE, Dattwyler RJ, Golde WT, Dunn JJ, Wang IN, Wormser GP, Schriefer ME, Luft BJ: Four clones of Borrelia burgdorferi sensu stricto cause invasive infection in humans. Infect Immun 1999, 67:3518-3524

41. Wormser GP, Liveris D, Nowakowski J, Nadelman RB, Cavaliere LF, McKenna D, Holmgren D, Schwartz l: Association of specific subtypes of Borrelia burgdorferi with hematogenous dissemination in early Lyme disease. J Infect Dis 1999, 180:720-725.

42. Baranton G, Seinost G, Theodore G, Postic D, Dykhuizen D: Distinct levels of genetic diversity of Borrelia burgdorferi are associated with different aspects of pathogenicity. Res Microbiol 2001, 152:149-156.

43. Alghaferi MY, Anderson JM, Park J, Auwaerter PG, Aucott JN, Norris DE, Dumler JS: Borrelia burgdorferi ospC heterogeneity among human and murine isolates from a defined region of northern Maryland and southern Pennsylvania: lack of correlation with invasive and noninvasive genotypes. J Clin Microbiol 2005, 43:1879-1884.

44. Crowder CD, Matthews HE, Schutzer S, Rounds MA, Luft BJ, Nolte O, Campbell SR, Phillipson CA, Li F, Sampath R, et al: Genotypic variation and mixtures of Lyme Borrelia in Ixodes ticks from North America and Europe. PLoS One 2010, 5:e10650.

45. Samuels D, Radolf J (Eds): Borrelia: Molecular Biology, Host Interaction and Pathogenesis. Norlfolk, UK: Caister Academic Press; 2010.

46. Safdie G, Farrah IY, Yahia R, Marva E, Wilamowski A, Sawalha SS, Wald N, Schmiedel J, Moter A, Gobel UB, et al: Molecular characterization of Borrelia persica, the agent of tick borne relapsing fever in Israel and the Palestinian Authority. PLoS One 2010, 5:e14105. 
47. Margos G, Vollmer SA, Ogden NH, Fish D: Population genetics, taxonomy, phylogeny and evolution of Borrelia burgdorferi sensu lato. Infect Genet Evol 2011, 11:1545-1563.

48. Margos G, Vollmer SA, Cornet M, Garnier M, Fingerle V, Wilske B, Bormane A, Vitorino L, Collares-Pereira M, Drancourt M, Kurtenbach K: A new Borrelia species defined by multilocus sequence analysis of housekeeping genes. Appl Environ Microbiol 2009, 75:5410-5416.

49. Qiu WG, Schutzer SE, Bruno JF, Attie O, Xu Y, Dunn JJ, Fraser CM, Casjens SR, Luft BJ: Genetic exchange and plasmid transfers in Borrelia burgdorferi sensu stricto revealed by three-way genome comparisons and multilocus sequence typing. Proc Natl Acad Sci U S A 2004, 101:14150-14155.

50. Schutzer SE, Fraser-Liggett CM, Casjens SR, Qiu WG, Dunn JJ, Mongodin EF, Luft BJ: Whole genome sequences of thirteen isolates of Borrelia burgdorferi. J Bacteriol 2011, 193:1018-1020.

51. Casjens S, Mongodin E, Qiu W, Dunn J, Luft B, Fraser-Liggett C, Schutzer S: Whole genome sequences of two Borrelia afzelii and two Borrelia garini Lyme disease agent isolate. J Bacteriol 2012, 193:6995-6996.

52. Schutzer SE, Fraser-Liggett CM, Qiu WG, Kraiczy P, Mongodin EF, Dunn JJ, Luft BJ, Casjens SR: Whole-genome sequences of Borrelia bissettii, Borrelia valaisiana, and Borrelia spielmanii. J Bacteriol 2012, 194:545-546.

53. Casjens SR, Fraser-Liggett CM, Mongodin EF, Qiu WG, Dunn JJ, Luft BJ, Schutzer SE: Whole genome sequence of an unusual Borrelia burgdorferi sensu lato isolate. J Bacterio/ 2011, 193:1489-1490.

54. Glöckner G, Schulte-Spechtel U, Schilhabel M, Felder M, Suhnel J, Wilske B, Platzer M: Comparative genome analysis: selection pressure on the Borrelia vls cassettes is essential for infectivity. BMC Genomics 2006, 7:211.

55. Casjens S, Delange M, Ley HL 3rd, Rosa P, Huang WM: Linear chromosomes of Lyme disease agent spirochetes: genetic diversity and conservation of gene order. J Bacterio/ 1995, 177:2769-2780

56. Casjens S, Murphy M, DeLange M, Sampson L, van Vugt R, Huang WM: Telomeres of the linear chromosomes of Lyme disease spirochaetes: nucleotide sequence and possible exchange with linear plasmid telomeres. Mol Microbiol 1997, 26:581-596.

57. Casjens S, Palmer N, van Vugt R, Huang WM, Stevenson B, Rosa P, Lathigra R, Sutton G, Peterson J, Dodson RJ, et al: A bacterial genome in flux: the twelve linear and nine circular extrachromosomal DNAs in an infectious isolate of the Lyme disease spirochete Borrelia burgdorferi. Mol Microbiol 2000, 35:490-516.

58. Huang WM, Robertson M, Aron J, Casjens S: Telomere exchange between linear replicons of Borrelia burgdorferi. J Bacteriol 2004, 186:4134-4141.

59. Casjens SR, Mongodin EF, Qiu WG, Luft BJ, Schutzer SE, Gilcrease EB, Huang WM, Vujadinovic M, Aron JK, Vargas LC, et al: Genome stability of Lyme disease spirochetes: comparative genomics of Borrelia burgdorferi plasmids. PLoS One 2012, 7:e33280.

60. Yang X, Nguyen A, Qiu D, Luft BJ: In vitro activity of tigecycline against multiple strains of Borrelia burgdorferi. J Antimicrob Chemother 2009, 63:709-712.

61. Yang X, Lenhart TR, Kariu T, Anguita J, Akins DR, Pal U: Characterization of unique regions of Borrelia burgdorferi surface-located membrane protein 1. Infect Immun 2010, 78:4477-4487.

62. Benson G: Tandem repeats finder: a program to analyze DNA sequences. Nucleic Acids Res 1999, 27:573-580.

63. Casjens S, Eggers CH, Schwartz I: Borrelia genomics: chromsosome, plasmids, bacteriophages and genetic variation. In Borrelia molecular biology, host interaction and pathogenicity. Edited by Samuels DS, Radolf J. Norfolk: Caister Academic Press; 2010:27-53.

64. Lescot M, Audic S, Robert C, Nguyen TT, Blanc G, Cutler SJ, Wincker P, Couloux A, Claverie JM, Raoult D, Drancourt M: The genome of Borrelia recurrentis, the agent of deadly louse-borne relapsing fever, is a degraded subset of tick-borne Borrelia duttonii. PLoS Genet 2008, 4:e1000185.

65. Toledo A, Anda P, Escudero R, Larsson C, Bergstrom S, Benach JL: Phylogenetic analysis of a virulent Borrelia species isolated from patients with relapsing fever. J Clin Microbiol 2010, 48:2484-2489.

66. Haven J, Vargas LC, Mongodin EF, Xue V, Hernandez Y, Pagan P, Fraser-Liggett CM, Schutzer SE, Luft BJ, Casjens SR, Qiu WG: Pervasive recombination and sympatric genome diversification driven by frequency-dependent selection in Borrelia burgdorferi, the Lyme disease bacterium. Genetics 2011, 189:951-966.

67. Liveris D, Wormser GP, Nowakowski J, Nadelman R, Bittker S, Cooper D, Varde S, Moy FH, Forseter G, Pavia CS, Schwartz I: Molecular typing of Borrelia burgdorferi from Lyme disease patients by PCR-restriction fragment length polymorphism analysis. J Clin Microbio/ 1996, 34:1306-1309.

68. Liveris D, Varde S, lyer R, Koenig S, Bittker S, Cooper D, McKenna D, Nowakowski J, Nadelman RB, Wormser GP, Schwartz I: Genetic diversity of Borrelia burgdorferi in lyme disease patients as determined by culture versus direct PCR with clinical specimens. J Clin Microbiol 1999, 37:565-569.

69. Tettelin H, Masignani V, Cieslewicz MJ, Donati C, Medini D, Ward NL, Angiuoli SV, Crabtree J, Jones AL, Durkin AS, et al: Genome analysis of multiple pathogenic isolates of Streptococcus agalactiae: implications for the microbial "pan-genome". Proc Natl Acad Sci U S A 2005, 102:13950-13955.

70. Tettelin H, Riley D, Cattuto C, Medini D: Comparative genomics: the bacterial pan-genome. Curr Opin Microbiol 2008, 11:472-477.

71. Tettelin $\mathrm{H}$ : The bacterial pan-genome and reverse vaccinology. Genome Dyn 2009, 6:35-47.

72. Riley DR, Angiuoli SV, Crabtree J, Dunning Hotopp JC, Tettelin H: Using Sybil for interactive comparative genomics of microbes on the web. Bioinformatics 2012, 28:160-166.

73. Budroni S, Siena E, Dunning Hotopp JC, Seib KL, Serruto D, Nofroni C, Comanducci M, Riley DR, Daugherty SC, Angiuoli SV, et al: Neisseria meningitidis is structured in clades associated with restriction modification systems that modulate homologous recombination. Proc Natl Acad Sci USA 2011, 108:4494-4499.

74. Eggers $\mathrm{CH}$, Casjens S, Samuels DS: Bacteriophages of Borrelia burgdorferi and other spirochetes. In The spirochetes Molecilar and celullar biology. Edited by Saier M, Garcia-Lara J. Wiltshire: Hozison Scientific Press; 2001:35-44.

75. Zhang $H$, Marconi RT: Demonstration of cotranscription and 1-methyl-3-nitroso-nitroguanidine induction of a 30-gene operon of Borrelia burgdorferi: evidence that the 32-kilobase circular plasmids are prophages. J Bacteriol 2005, 187:7985-7995.

76. Touchon M, Hoede C, Tenaillon O, Barbe V, Baeriswyl S, Bidet P, Bingen E, Bonacorsi S, Bouchier C, Bouvet $O$, et al: Organised genome dynamics in the Escherichia coli species results in highly diverse adaptive paths. PLoS Genet 2009, 5:e1000344.

77. Donati C, Hiller NL, Tettelin H, Muzzi A, Croucher NJ, Angiuoli SV, Oggioni M, Dunning Hotopp JC, Hu FZ, Riley DR, et al: Structure and dynamics of the pan-genome of Streptococcus pneumoniae and closely related species. Genome Biol 2010, 11:R107.

78. Snipen L, Almoy T, Ussery DW: Microbial comparative pan-genomics using binomial mixture models. BMC Genomics 2009, 10:385

79. Mann RA, Smits TH, Buhlmann A, Blom J, Goesmann A, Frey JE, Plummer KM, Beer SV, Luck J, Duffy B, Rodoni B: Comparative genomics of 12 strains of Enwinia amylovora identifies a pan-genome with a large conserved core. PLoS One 2013, 8:e55644.

80. Yang Z: PAML 4: phylogenetic analysis by maximum likelihood. Mol Biol Evol 2007, 24:1586-1591.

81. Wywial E, Haven J, Casjens SR, Hernandez YA, Singh S, Mongodin EF Fraser-Liggett CM, Luft BJ, Schutzer SE, Qiu WG: Fast, adaptive evolution at a bacterial host-resistance locus: the PFam54 gene array in Borrelia burgdorferi. Gene 2009, 445:26-37.

82. Charlesworth J, Eyre-Walker A: The rate of adaptive evolution in enteric bacteria. Mol Biol Evol 2006, 23:1348-1356.

83. Cassatt DR, Patel NK, Ulbrandt ND, Hanson MS: DbpA, but not OspA, is expressed by Borrelia burgdorferi during spirochetemia and is a target for protective antibodies. Infect Immun 1998, 66:5379-5387.

84. Grimm D, Tilly K, Byram R, Stewart PE, Krum JG, Bueschel DM, Schwan TG, Policastro PF, Elias AF, Rosa PA: Outer-surface protein C of the Lyme disease spirochete: a protein induced in ticks for infection of mammals. Proc Natl Acad Sci USA 2004, 101:3142-3147

85. Liang FT, Brown EL, Wang T, lozzo RV, Fikrig E: Protective Niche for Borrelia burgdorferi to evade humoral immunity. Am J Pathol 2004, 165:977-985.

86. Fraser CM, Casjens S, Huang WM, Sutton GG, Clayton R, Lathigra R, White $O$, Ketchum KA, Dodson R, Hickey EK, et al: Genomic sequence of a Lyme disease spirochaete, Borrelia burgdorferi. Nature 1997, 390:580-586.

87. Takahata N: Evolutionary genetics of human paleo-populations. In Mechanisms of Molecular Evolution. Edited by Takahata N, Clark AG. Tokyo: Japan Scientific Societies Press; 1993:1-21.

88. Ogden NH, Margos G, Aanensen DM, Drebot MA, Feil EJ, Hanincova K, Schwartz I, Tyler S, Lindsay LR: Investigation of genotypes of Borrelia burgdorferi in Ixodes scapularis ticks collected during surveillance in Canada. Appl Environ Microbiol 2011, 77:3244-3254. 
89. Rudenko N, Golovchenko M, Grubhoffer L, Oliver JH Jr: Updates on Borrelia burgdorferi sensu lato complex with respect to public health. Ticks Tick Borne Dis 2011, 2:123-128.

90. Schierup $\mathrm{MH}$, Mikkelsen $\mathrm{AM}$, Hein J: Recombination, balancing selection and phylogenies in MHC and self-incompatibility genes. Genetics 2001, 159:1833-1844.

91. Larkin MA, Blackshields G, Brown NP, Chenna R, McGettigan PA, McWilliam H, Valentin F, Wallace IM, Wilm A, Lopez R: Clustal W and Clustal X version 2.0. Bioinformatics 2007, 23:2947-2948.

92. Ronquist F, Huelsenbeck JP: MrBayes 3: Bayesian phylogenetic inference under mixed models. Bioinformatics 2003, 19:1572-1574.

93. Felsenstein J: PHYLIP -- Phylogeny Inference Package (Version 3.2). Cladistics 1989, 5:164-166.

94. Nelson KE, Fouts DE, Mongodin EF, Ravel J, DeBoy RT, Kolonay JF, Rasko DA, Angiuoli SV, Gill SR, Paulsen IT, et al: Whole genome comparisons of serotype $4 \mathrm{~b}$ and $1 / 2 \mathrm{a}$ strains of the food-borne pathogen Listeria monocytogenes reveal new insights into the core genome components of this species. Nucleic Acids Res 2004, 32:2386-2395.

95. Sutton $G$, White O, Adams M, Kerlavage A: TIGR assembler: a new tool for assembling large shotgun sequencing projects. Genome Science and Technology 1995, 01:9-19.

96. Myers EW, Sutton GG, Delcher AL, Dew IM, Fasulo DP, Flanigan MJ, Kravitz SA, Mobarry CM, Reinert KH, Remington KA, et al: A whole-genome assembly of Drosophila. Science 2000, 287:2196-2204.

97. Biery MC, Stewart FJ, Stellwagen AE, Raleigh EA, Craig NL: A simple in vitro Tn7-based transposition system with low target site selectivity for genome and gene analysis. Nucleic Acids Res 2000, 28:1067-1077.

98. Delcher AL, Phillippy A, Carlton J, Salzberg SL: Fast algorithms for large-scale genome alignment and comparison. Nucleic Acids Res 2002, 30:2478-2483.

99. Pop M, Kosack D: Using the TIGR assembler in shotgun sequencing projects. Methods Mol Biol 2004, 255:279-294.

100. Angiuoli SV, Salzberg SL: Mugsy: fast multiple alignment of closely related whole genomes. Bioinformatics 2011, 27:334-342.

101. Delcher A, Salzberg S, Phillippy A: Using MUMmer to identify similar regions in large sequence sets. In Curr Protoc Bioinformatics 2003, Chapter 10:Unit 10.3.

102. Doring A, Weese D, Rausch T, Reinert K: SeqAn an efficient, generic C++ library for sequence analysis. BMC Bioinforma 2008, 9:11

103. Price MN, Dehal PS, Arkin AP: FastTree 2-approximately maximum-likelihood trees for large alignments. PLoS One 2010, 5:e9490.

104. Rice P, Longden I, Bleasby A: EMBOSS: the European molecular biology open software suite. Trends Genet 2000, 16:276-277.

105. Altschul SF, Madden TL, Schaffer AA, Zhang J, Zhang Z, Miller W, Lipman DJ: Gapped BLAST and PSI-BLAST: a new generation of protein database search programs. Nucleic Acids Res 1997, 25:3389-3402.

106. Stajich JE, Block D, Boulez K, Brenner SE, Chervitz SA, Dagdigian C, Fuellen G, Gilbert JG, Korf I, Lapp H, et al: The Bioperl toolkit: Perl modules for the life sciences. Genome Res 2002, 12:1611-1618.

107. Crabtree J, Angiuoli SV, Wortman JR, White OR: Sybil: methods and software for multiple genome comparison and visualization. Methods $\mathrm{Mol}$ Biol 2007, 408:93-108.

108. Orvis J, Crabtree J, Galens K, Gussman A, Inman JM, Lee E, Nampally S, Riley D, Sundaram JP, Felix V, et al: Ergatis: a web interface and scalable software system for bioinformatics workflows. Bioinformatics 2010, 26:1488-1492

109. Haiko J, Kukkonen M, Ravantti JJ, Westerlund-Wikstrom B, Korhonen TK: The single substitution I259T, conserved in the plasminogen activator Pla of pandemic Yersinia pestis branches, enhances fibrinolytic activity. J Bacteriol 2009, 191:4758-4766.

110. Goldman N, Yang Z: A codon-based model of nucleotide substitution for protein-coding DNA sequences. Mol Biol Evol 1994, 11:725-736.

111. Nee S, May RM, Harvey PH: The reconstructed evolutionary process. Philos Trans R Soc Lond B Biol Sci 1994, 344:305-311.

112. Burgdorfer W, Barbour AG, Hayes SF, Benach JL, Grunwaldt E, Davis JP: Lyme disease-a tick-borne spirochetosis? Science 1982, 216:1317-1319.

113. Simon MM, Schaible UE, Kramer MD, Eckerskorn C, Museteanu C, Muller-Hermelink HK, Wallich R: Recombinant outer surface protein a from Borrelia burgdorferi induces antibodies protective against spirochetal infection in mice. J Infect Dis 1991, 164:123-132

114. Qiu WG, Dykhuizen DE, Acosta MS, Luft BJ: Geographic uniformity of the Lyme disease spirochete (Borrelia burgdorferi) and its shared history with tick vector (Ixodes scapularis) in the Northeastern United States. Genetics 2002, 160:833-849.

115. Steere AC, Grodzicki RL, Kornblatt AN, Craft JE, Barbour AG, Burgdorfer W Schmid GP, Johnson E, Malawista SE: The spirochetal etiology of Lyme disease. N Engl J Med 1983, 308:733-740.

116. McLean RG, Ubico SR, Hughes CA, Engstrom SM, Johnson RC: Isolation and characterization of Borrelia burgdorferi from blood of a bird captured in the Saint Croix River Valley. J Clin Microbiol 1993, 31:2038-2043.

117. Piesman J, Mather TN, Sinsky RJ, Spielman A: Duration of tick attachment and Borrelia burgdorferi transmission. J Clin Microbiol 1987, 25:557-558.

118. Rosa P, Hogan D, Schwan T: Polymerase chain reaction analyses identify two distinct classes of Borrelia burgdorferi. J Clin Microbiol 1991, 29:524-532.

119. Barthold SW, Moody KD, Terwilliger GA, Duray PH, Jacoby RO, Steere AC: Experimental Lyme arthritis in rats infected with Borrelia burgdorferi. J Infect Dis 1988, 157:842-846.

120. Zingg BC, Anderson JF, Johnson RC, LeFebvre RB: Comparative analysis of genetic variability among Borrelia burgdorferi isolates from Europe and the United States by restriction enzyme analysis, gene restriction fragment length polymorphism, and pulsed- field gel electrophoresis. J Clin Microbiol 1993, 31:3115-3122.

121. Peter O, Bretz AG: Polymorphism of outer surface proteins of Borrelia burgdorferi as a tool for classification. Zentralbl Bakeriol 1992, 277:28-33.

122. Kurashige S, Bissett M, Oshiro L: Characterization of a tick isolate of Borrelia burgdorferi that possesses a major low-molecular-weight surface protein. J Clin Microbiol 1990, 28:1362-1366

123. Preac-Mursic V, Wilske B, Schierz G: European Borrelia burgdorferi isolated from humans and ticks culture conditions and antibiotic susceptibility. Zentralbl Bakteriol Mikrobiol Hyg [A] 1986, 263:112-118.

124. Åsbrink E, Hederstedt B, Hovmark A: A spirochetal etiology of acrodermatitis chronica atrophicans Herxheimer. Acta Dermatol Venereol 1984, 64:506-512.

125. Gylfe Olsen B, Strasevicius D, Marti Ras N, Weihe P, Noppa L, Ostberg Y, Baranton G, Bergstrom S: Isolation of Lyme disease Borrelia from puffins (Fratercula arctica) and seabird ticks (Ixodes uriae) on the Faeroe Islands. J Clin Microbiol 1999, 37:890-896.

126. Wilske B, Preac-Mursic V, Gobel UB, Graf B, Jauris S, Soutschek E, Schwab E, Zumstein G: An OspA serotyping system for Borrelia burgdorferi based on reactivity with monoclonal antibodies and OspA sequence analysis. J Clin Microbiol 1993, 31:340-350.

127. Wang G, van Dam AP, Dankert J: Phenotypic and genetic characterization of a novel Borrelia burgdorferi sensu lato isolate from a patient with lyme borreliosis. J Clin Microbiol 1999, 37:3025-3028.

doi:10.1186/1471-2164-14-693

Cite this article as: Mongodin et al:: Inter- and intra-specific pangenomes of Borrelia burgdorferi sensu lato: genome stability and adaptive radiation. BMC Genomics 2013 14:693.

\section{Submit your next manuscript to BioMed Central and take full advantage of:}

- Convenient online submission

- Thorough peer review

- No space constraints or color figure charges

- Immediate publication on acceptance

- Inclusion in PubMed, CAS, Scopus and Google Scholar

- Research which is freely available for redistribution 